\title{
REVIEW
}

\section{Novel actions of sclerostin on bone}

\author{
Gill Holdsworth, Scott J Roberts and Hua Zhu Ke ${ }^{\dagger}$ \\ Bone Therapeutic Area, UCB Pharma, Slough, United Kingdom
}

Correspondence should be addressed to G Holdsworth: Gill.Holdsworth@ucb.com

${ }^{\dagger}(\mathrm{H}$ Z Ke is now at Angitia Biopharmaceuticals, Guangzhou, China)

\begin{abstract}
The discovery that two rare autosomal recessive high bone mass conditions were caused by the loss of sclerostin expression prompted studies into its role in bone homeostasis. In this article, we aim to bring together the wealth of information relating to sclerostin in bone though discussion of rare human disorders in which sclerostin is reduced or absent, sclerostin manipulation via genetic approaches and treatment with antibodies that neutralise sclerostin in animal models and in human. Together, these findings demonstrate the importance of sclerostin as a regulator of bone homeostasis and provide valuable insights into its biological mechanism of action. We summarise the current state of knowledge in the field, including the current understanding of the direct effects of sclerostin on the canonical WNT signalling pathway and the actions of sclerostin as an inhibitor of bone formation. We review the effects of sclerostin, and its inhibition, on bone at the cellular and tissue level and discuss new findings that suggest that sclerostin may also regulate adipose tissue. Finally, we highlight areas in which future research is expected to yield additional insights into the biology of sclerostin.
\end{abstract}
Key Words
- sclerostin
- bone
- WNT signalling
- osteoporosis

\section{Introduction}

One consequence of advances in modern medicine is an ageing global population and a concomitant increase in age-related conditions. Peak bone mass is typically reached in early adulthood, after which, bone quantity and quality decline with advancing years (Riggs \& Melton 1986, Boskey \& Imbert 2017). Osteoporosis is a prevalent skeletal disorder characterised by reduced bone strength with an associated increased risk of fracture (NIH Consensus Development Panel on Osteoporosis Prevention and Therapy 2001), and approximately 1 in 5 men and 1 in 3 women aged over 50 years will experience a fragility fracture in their remaining lifetime (Cooper \& Ferrari 2017). Fragility fractures that occur following low trauma are often the first indication that loss of bone mass and strength has occurred due to dysregulation of the balance between bone formation and bone resorption. Osteoporosis presents a significant burden to the patient and health care systems; hence, there has been great interest in gaining a deeper understanding into the signalling pathways that regulate bone homeostasis.

Insights gained from rare monogenic diseases can identify central pathways and critical nodes involved in tissue homeostasis. Mutations that affect expression of the protein encoded by the SOST gene are found in patients with two very rare high bone mass conditions, highlighting the SOST gene product, sclerostin, as a critical regulator of bone formation and prompting a vast amount of research into its biology. Sclerostin is now understood to act as an antagonist of the canonical WNT signalling pathway in osteoblast lineage cells, thereby negatively regulating bone formation. Inhibition of sclerostin has been proposed as a therapeutic target in bone diseases and 
neutralising antibodies to sclerostin (Scl-Ab) have been evaluated in animal models and in clinical trials (reviewed by Lovato \& Lewiecki 2017, McClung 2017, Ominsky et al. 2017a, Canalis 2018).

In this review, we summarise the current literature on the biology and mechanism of action of sclerostin in the skeleton and beyond and draw attention to areas in which additional research will further increase our understanding of this fascinating protein.

\section{Human conditions related to mutation of the SOST gene}

The rare monogenic bone disorders sclerosteosis and van Buchem disease display a recessive Mendelian pattern of inheritance, where the presence of two mutant alleles results in development of the disease phenotype. These closely related conditions were first described in the 1950 s (Van Buchem et al. 1955, Truswell 1958) and are caused by different mutations which each affect the SOST gene, causing loss of its protein product, sclerostin. Unlike many osteoporotic high bone mass conditions, which reflect a defect in bone resorption, mutations in SOST are associated with increased bone formation (hyperostosis). Patients with sclerosteosis and van Buchem disease exhibit generalised skeletal sclerosis, leading to increased bone mineral density throughout the skeleton with the greatest prominence at the base of the skull, jaw and long bones (van Lierop et al. 2017). Similarities in the clinical and radiographic features of these patients lead to speculation that the conditions might result from mutations in the same gene and could reflect common ancestry (Beighton et al. 1984). Genome-wide linkage analysis performed in patients with van Buchem disease and sclerosteosis mapped the causative mutation(s) to chromosome 17q12-q21 (Van Hul et al. 1998, Balemans et al. 1999). Subsequently, homozygosity mapping and positional cloning revealed that although these two conditions were indeed caused by mutations that affected the same gene, the genetic lesions underlying each disease were quite distinct in their locations, thus disproving the common ancestor hypothesis. The causative mutations in sclerosteosis and van Buchem disease are discussed in more detail below.

\section{Sclerosteosis}

Sclerosteosis is predominantly found in the Afrikaner community of South Africa, although a small number of cases have been reported in other countries (van Lierop et al. 2017). Patients are typically of tall stature and syndactyly (fusion of the digits) is often seen and where present, is the earliest postnatal indicator of the disease. Compression of the cranial nerves is frequently present and causes facial palsy and deafness. Thickening of the calvarium can lead to potential lethal elevation of intracranial pressure and this severe clinical manifestation of sclerosteosis is currently managed through complex decompression surgery. Interestingly, the disease is not associated with increased risk of fracture, and the lack of ectopic bone and absence of obvious effects on nonskeletal tissues suggests the defective gene does not have widespread pleiotropic effects. Heterozygous carriers of sclerosteosis have one wild type and one faulty copy of the SOST gene and do not exhibit the profound skeletal phenotype associated with the autosomal recessive disease. However, carriers do have increased bone mineral density (BMD), and levels of circulating sclerostin protein in these individuals are approximately 60\% lower compared with controls (van Lierop et al. 2017). In 2001, two groups independently reported lossof-function mutations in the SOST gene of sclerosteosis patients that result in loss of sclerostin expression due to the presence of a premature stop codon in the amino terminus of the protein (Balemans et al. 2001, Brunkow et al. 2001). Subsequently, additional sclerosteosis-related SOST mutations have been identified, all of which result in the failure to produce active sclerostin protein (van Lierop et al. 2017).

\section{van Buchem disease}

Van Buchem disease is another rare monogenic autosomal recessive bone sclerosing disorder. Patients with this condition almost invariably originate from an isolated village in the Netherlands and the founder mutation underlying most of these cases has been traced back to 1751 (Van Hul et al. 1998). The skeletal phenotype shares several similarities with sclerosteosis; however, patients tend to be normal height and do not display syndactyly. These differences reflect the divergence of the mutations present in these two conditions. In contrast to the SOST gene mutation found in sclerosteosis, van Buchem patients harbour a $52 \mathrm{~kb}$ homozygous deletion of a noncoding enhancer element located $35 \mathrm{~kb}$ downstream of the SOST gene, which is required for postnatal expression of sclerostin (Balemans et al. 2002, Loots et al. 2005). 


\section{Craniodiaphyseal dysplasia}

Craniodiaphyseal dysplasia (CDD) is characterised by facial distortion due to massive generalised hyperostosis and sclerosis of the skull and facial bone. CDD is extremely rare and in this severe disease, increased bone deposition around the craniofacial foramina causes respiratory difficulties that are evident at birth and limit the lifespan of affected individuals. Unlike the recessive inheritance pattern of sclerosteosis and van Buchem disease, the genetic transmission of CDD is not well understood. Two patients with CDD were reported to harbour de novo heterozygous autosomal dominant mutations in SOST that introduced missense mutations in the sclerostin signal peptide cleavage site, preventing secretion of sclerostin protein from transfected cells in vitro (Kim et al. 2011). Interestingly, it was recently reported that endoplasmic reticulum (ER) stress caused by retention of a mutant protein in the osteocyte was associated with a generalised progressive hyperostosis with similarities to CDD (Chan et al. 2017). In this work, expression of a truncated variant of the collagen type $X$ alpha 1 chain (Col10a1) gene in transgenic mice resulted in production of collagen X chains, which were poorly secreted from the cell. Accumulation of this mutant protein promoted ER stress and activation of the unfolded protein response in immature osteocytes, delaying their maturation and increasing the duration of bone formation. Hence, the more severe phenotype observed in the autosomal dominant condition of CDD compared with sclerosteosis and van Buchem disease could reflect a compound effect due to both reduced sclerostin secretion and activation of the unfolded protein response in osteocytes.

\section{WNT signalling}

\section{Overview of WNT signalling}

Signalling by wingless-related integration site (WNT) proteins represents an evolutionary conserved pathway that has a key role in developmental regulation and adult tissue homeostasis. This ancient signal transduction cascade is found throughout the animal kingdom, including the primitive organisms hydra and sea sponge. In higher mammals, it is immensely complex: in humans there are 19 WNT ligands, each encoded by a separate gene, and there are ten cell-surface frizzled (FZD) receptors and several WNT co-receptors, which direct signalling along one of three distinct intracellular pathways in response to the WNT stimulus. Of these pathways, the canonical WNT- $\beta$-catenin pathway is most well studied and is the one upon which sclerostin acts (reviewed by Baron \& Kneissel 2013, Nusse \& Clevers 2017). The two noncanonical branches of WNT signalling (WNT-planar cell polarity and WNT-calcium) are beyond the scope of this article and will not be discussed further here, however, they have been reviewed elsewhere (Niehrs 2012, Nusse \& Clevers 2017).

The intracellular abundance and location of $\beta$-catenin provides a central switch in the canonical WNT signalling pathway. Regulation of this pathway has been the subject of much research in the 30 years since the discovery of the first mammalian WNT gene, and a simplified overview which summarises the key components of the canonical WNT- $\beta$ catenin signalling pathway in the activated ('WNT $\mathrm{ON}^{\prime}$ ) and basal/inhibited ('WNT OFF') states is presented in Fig. 1. The fate of cytoplasmic $\beta$-catenin is controlled by the actions of the multi-protein $\beta$-catenin-containing destruction complex, in which AXIN and adenomatous polyposis coli (APC) are associated with dishevelled (DVL), $\beta$-catenin, casein kinase 1 (CK1) and glycogen synthase kinase 3 beta (GSK3 3 ), which are constitutively active enzymes that phosphorylate $\beta$-catenin. Canonical WNT signalling occurs in an autocrine or paracrine fashion and is triggered by binding of WNT ligand to the low-density lipoprotein receptor-related protein 5/6 (LRP5/6) WNT co-receptors and FZD to promote formation of a ternary complex ('WNT ON' in Fig. 1), leading to phosphorylation of the cytoplasmic domain of LRP5/6. Interactions between the intracellular regions of LRP5/6 with AXIN, and FZD with DVL, respectively, localise the destruction complex to the cell membrane, inhibiting the activity of the associated kinases. Nonphosphorylated $\beta$-catenin accumulates in the cytoplasm and translocates to the nucleus, where it associates with DNA-bound T-cell factor/lymphoid enhancer factor (TCF/LEF) transcription factors to initiate transcription of $W N T$ target genes.

In common with other morphogenic pathways, tight control of WNT pathway activation is required, and one way in which this is achieved is via the existence of multiple secreted antagonists. These may be subdivided into broad classes: those that bind WNT ligands or those that bind WNT co-receptors. Sclerostin falls into the latter category. In the basal or sclerostin-inhibited state ('WNT

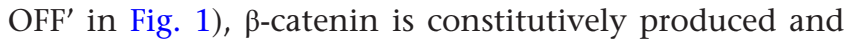
degraded through the actions of the destruction complex. Phosphorylation of $\beta$-catenin by CK1 and GSK3 $\beta$ labels it for ubiquitination and proteasomal degradation, preventing its accumulation and nuclear translocation. In the absence of nuclear $\beta$-catenin, TCF/LEF is associated 


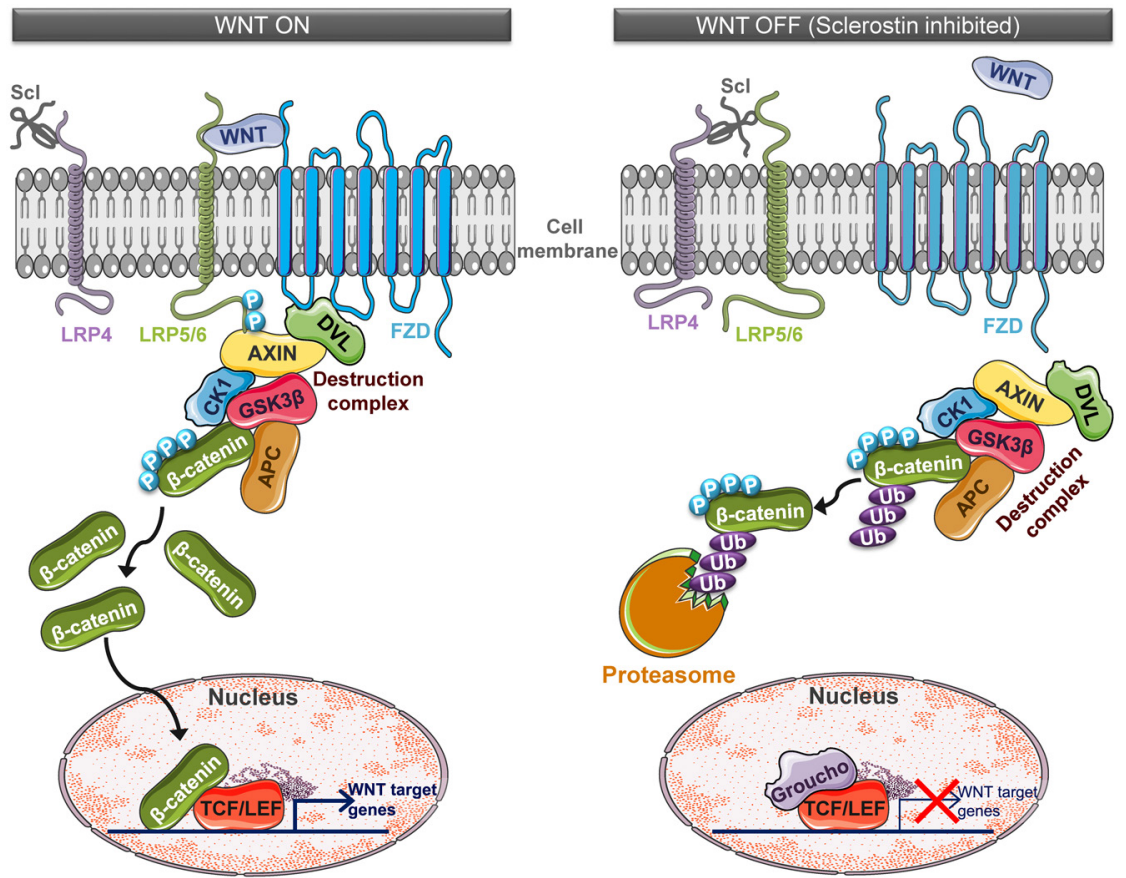

\section{Figure 1}

A simplified overview of the canonical WNT signalling pathway, and its inhibition by sclerostin. In the WNT ON state, extracellular WNT ligands bind the LRP5/6 cell surface receptor and a frizzled (FZD) family cell-surface receptor to form a ternary complex, leading to translocation of the destruction complex to the cell membrane, phosphorylation of the intracellular region of LRP5/6 and recruitment of AXIN which disrupts destruction complex activity. Non-phosphorylated $\beta$-catenin accumulates in the cytoplasm and translocates to the nucleus where it binds the TCF/LEF transcription factors to initiate transcription of WNT target genes. In the WNT OFF (sclerostin inhibited) state, sclerostin (Scl) binds to the LRP4 and LRP5/6 cell-surface receptors, preventing the interaction between WNT ligands with LRP5/6. This prevents formation of the LRP5/6-WNT-FZD ternary complex and hence inhibits canonical WNTsignalling. Cytosolic $\beta$-catenin is phosphorylated and targeted for ubiquitination by the destruction complex and degraded in the proteasome. TCF/LEF transcription factors in the nucleus are associated with Groucho and WNT target gene transcription is repressed. This figure was produced using Servier Medical Art.

with the transcriptional repressor Groucho and is maintained in an inactive state.

\section{Canonical WNT signalling in bone}

Recognition of the importance of the canonical WNT pathway as a regulator of bone mass came through the discovery of mutations in the LRP5 WNT co-receptor that were associated with altered bone density. Loss-offunction mutations were described in patients with the low bone mass condition osteoporosis pseudoglioma (OPPG) (Gong et al. 2001) whilst missense mutations in the extracellular domain were found in patients with high bone mass (Van Wesenbeeck et al. 2003, Little et al. 2017). Canonical WNT signalling promotes bone formation through its effects on mesenchymal stem cells (MSC) and activation of the pathway promotes commitment to, and differentiation towards, the osteoblastic lineage whilst inhibiting adipogenic and chondrogenic commitment (reviewed by Baron \& Kneissel 2013, Lerner \& Ohlsson 2015). In addition to favouring bone formation, canonical WNT signalling also decreases bone resorption by increasing expression of the WNT target gene osteoprotegerin (OPG), which acts as a decoy receptor for receptor activator of nuclear factor- $\kappa \mathrm{B}$ ligand (RANKL) to inhibit osteoclastogenesis (Glass et al. 2005).

\section{Sclerostin}

\section{Expression}

Sclerostin is expressed in the mouse limb bud and skeletal anlage during embryogenesis (Loots et al. 2005), and its involvement with limb patterning in mice is consistent with the syndactyly reported in some sclerosteosis patients (Collette et al. 2016). In the adult, expression is largely restricted to the skeleton where it is produced by mature osteocytes but not by early osteocytes, osteoblasts or bone lining cells (Poole et al. 2005). Sclerostin is expressed at lower levels in other cells associated with mineralised matrix, including cementocytes, hypertrophic and articular chondrocytes, as well as synovial fibroblasts 
(Chouinard et al. 2016, Wehmeyer et al. 2016). In mice, Sost mRNA is expressed in vascular smooth muscle cells of the great arteries during embryonic and neonatal development (van Bezooijen et al. 2007) whilst sclerostin protein is present in human aorta (Didangelos et al. 2010, Krishna et al. 2017). Its expression is upregulated in the foci of vascular calcification (Zhu et al. 2011, Zhou et al. 2017), where it has been proposed as a potential regulator of mineralisation.

Expression of sclerostin in osteocytes is inversely related to mechanical loading in vivo and in ex vivo bone explant cultures (Robling et al. 2008, Kogawa et al. 2018), in line with the proposed role of the osteocyte as a skeletal mechanosensor. SOST mRNA was expressed at similar abundance in bone biopsies collected from young (22-44 years) and old (64-88 years) women, indicating that bone sclerostin mRNA levels do not increase with age (Roforth et al. 2014). Apart from sclerosteosis patients, in whom it is not detected, sclerostin protein is present in the circulation and its levels are reported to increase with age (Roforth et al. 2014, van Lierop et al. 2017). Immobilisation is associated with decreased BMD and increased serum sclerostin in animal models and humans (Robling et al. 2008, Clarke \& Drake 2013, Spatz et al. 2013).

The consequences of sclerostin overexpression have been investigated in rodents. Liver-directed adenoassociated viral (AAV) was used to systemically overexpress sclerostin in mice and increased serum sclerostin by approximately $65 \%$, resulting in modest reductions in femoral and vertebral trabecular bone fraction (Kim et al. 2017a). Similarly, long-term liver expression of exogenous sclerostin following hydrodynamic transfection resulted in approximately two-fold higher serum sclerostin concentration and a small reduction in trabecular bone fraction in the tibia (Zhang et al. 2016). Whilst these findings suggest that systemic sclerostin may contribute to skeletal homeostasis, the relevance of circulating sclerostin on the skeleton is not fully understood. The actions of sclerostin within the skeleton are thought to reflect the local activity of the protein following its release from osteocytes (Poole et al. 2005). Circulating sclerostin does not always correlate with bone density and mutations in the LRP4 sclerostin co-receptor which impair sclerostin binding are associated with significantly increased circulating sclerostin and increased bone mass (Fijalkowski et al. 2016).

Extracellular vesicles (EV) are nanoscale membrane vesicles released from cells. They are categorised by size and the manner of their release: exosomes (less than $150 \mathrm{~nm}$ in diameter) arise from fusion of late endosomes with the plasma membrane, whilst microvesicles and apoptotic bodies are typically at least $100 \mathrm{~nm}$ in diameter and are released directly from the plasma membrane (Hessvik \& Llorente 2018). Exosomes are believed to facilitate intercellular communication and have been the subject of much research in recent years. Osteocytes release EV in vivo (Wang et al. 2017). The quantity of EVs released and their composition may reflect cellular conditions and ex vivo studies on intact bones subjected to mechanical stimulation found that osteocyte $\mathrm{EV}$ release is upregulated in a calcium-dependent manner (Morrell et al. 2018). Importantly, EV released from osteocyte cell lines contain regulatory proteins including RANKL, OPG and sclerostin (Wang et al. 2017, Morrell et al. 2018), suggesting this mechanism may represent part of the skeletal response to mechanical load.

\section{Biochemistry and structure}

Following discovery of the SOST gene, analysis of the 213 long primary amino acid sequence of its protein product identified sclerostin as a potential new member of the Dan/Cerberus family of bone morphogenetic protein (BMP) antagonists (Brunkow et al. 2001). In common with other family members, sclerostin is a secreted glycoprotein that contains a cysteine knot motif, however, unlike the prototypical BMP antagonists, it lacks free cysteine residue which mediates dimerization in other examples of this protein class. Sclerostin contains two potential N-linked glycosylation sites, which are conserved across species, and it contains many positively charged lysine and arginine residues, giving it a predicted isoelectric point (pI) of approximately 9.5. Expression in mammalian systems yields a mature 190 amino acid protein, which runs as a doublet on SDS-PAGE (Krause et al. 2010, Holdsworth et al. 2012), likely reflecting differences in the extent of glycosylation. The functional significance of this post-translational modification is unclear since protein produced in $E$. coli was shown to be similarly effective in a WNT reporter assay compared with sclerostin produced in mammalian systems (Veverka et al. 2009).

Structural studies revealed sclerostin exists in solution as a highly flexible monomer comprising ordered and disordered regions (Veverka et al. 2009, Weidauer et al. 2009). The principal features of the sclerostin structure include $\mathrm{N}$ - and $\mathrm{C}$-terminal arms, which are disordered in the free solution state, and three loops which are formed around the cysteine knot motif. The so-called loops 1 and 3 have the cysteine knot at their base and their tips are 
held in constraint by a further disulphide bond to give a structured core to the protein. Loop 2, which exists on the opposing side of the cysteine knot, is highly mobile in solution and has been recognised as a functionally critical region of the protein that binds LRP5/6 (Holdsworth et al. 2012). Other notable features of the structure include a hydrophobic patch that is a potential protein interaction site located on the concave face of the core formed by loops 1 and 3, whilst the linear stretch of positively charged residues found down one side of the protein was shown to bind heparin (Veverka et al. 2009). Figure 2 shows an overlay of structures obtained for human sclerostin in solution, along with a ribbon cartoon showing key regions of functional importance.

\section{Interactions with cell-surface receptors and glycosaminoglycans}

Sclerostin binds the first beta propeller (E1) of the LRP5/6 WNT co-receptors to inhibit canonical WNT signalling (Li et al. 2005, Semenov et al. 2005, Holdsworth et al. 2012). The LRP5/6 extracellular domain contains four beta propellers and WNT ligands can be subcategorised based on their interaction with these propellers. WNT1 class ligands bind propeller 1 (E1) whilst the WNT3a class binds propeller 3 (E3) (Bourhis et al. 2010, Ettenberg et al. 2010). Consistent with this, sclerostin preferentially inhibits WNT1 class canonical signalling or binding (Bourhis et al. 2011, Holdsworth et al. 2012). In contrast, the Dickkopf (Dkk) family of WNT antagonists can bind E1 or E3 and thus inhibit both WNT1 and WNT3a class signalling (Bourhis et al. 2010, Patel et al. 2018). The existence of propeller-selective WNT antagonists may provide an additional level of fine tuning to regulate the Wnt signalling.

High-affinity binding of sclerostin to LRP5/6 is dependent on the conserved ' $\mathrm{NxI}$ ' motif found in loop 2 of sclerostin (shown in Fig. 2), in which an asparagine (N) and an isoleucine (I) residue are separated by any amino acid $(\mathrm{x})$. Mutation of the $\mathrm{N}$ or I position significantly reduced the efficacy of sclerostin as an inhibitor in a WNT-stimulated reporter assay (Bourhis et al. 2011, Holdsworth et al. 2012). The interaction of loop 2 with the first propeller of LRP5/6 is essential for inhibition of WNT signalling, however, several observations imply the existence of additional contacts between sclerostin and LRP5/6. Firstly, sclerostin binds approximately 10 -fold more strongly to a purified protein containing the first and second beta propellers of LRP6 (E1E2) than to LRP6 E1 alone (Bourhis et al. 2011). Secondly, cyclic
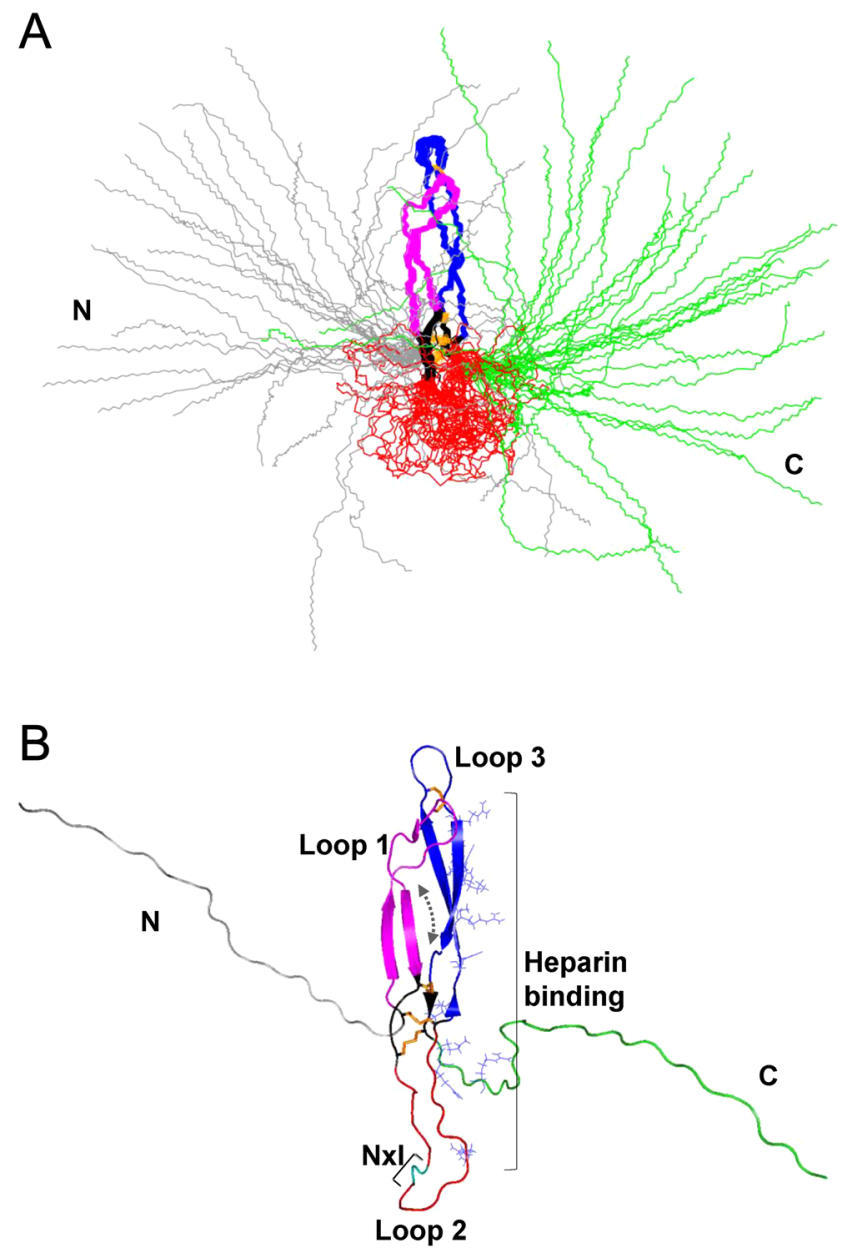

Figure 2

Structure and features of sclerostin. (A) Overlay of solution structures obtained for sclerostin determined by NMR. The amino-terminal (N) and carboxy-terminal $(C)$ arms of the protein are highly flexible and are shown in grey and green, respectively and have been partially truncated for clarity (residues 30-170 are shown). Three loops emanate from the central cysteine knot, which is shown in black with the disulphide bonds coloured orange. Loop 1 (shown in magenta) and loop 3 (shown in blue) are rigid and are joined by a disulphide bond (in orange) at their tips while the other loop (loop 2, shown in red) is highly flexible and unstructured. Republished with permission of American Society for Biochemistry and Molecular Biology, from Characterization of the Structural Features and Interactions of Sclerostin MOLECULAR INSIGHT INTO A KEY REGULATOR OF WNT-MEDIATED BONE FORMATION, V Veverka, 184 (16), 2009; permission conveyed through Copyright Clearance Center, Inc. (B) Ribbon cartoon of the sclerostin protein, showing the backbone topology of the structured core of the protein (Protein Data Bank accession number $2 \mathrm{~K} 8 \mathrm{P})$. The amino acid range of the protein and colour scheme are the same in (A). Additional structural features are marked: the loop $2 \mathrm{NxI}$ motif which interacts with the first propeller of LRP5/6 is shown in teal and residues believed to be involved in heparin binding are indicated by blue side chains. The dotted grey curved arrow indicates the location of the hydrophobic pocket on the concave surface between loops 1 and 3 .

peptides derived from loop 2 of sclerostin bind LRP6 E1 or E1E2 with similar affinity; however, this interaction is approximately two orders of magnitude weaker compared 
with the binding of full-length sclerostin to the same LRP6 protein (Bourhis et al. 2010, Holdsworth et al. 2012). Together, these data suggest that currently unidentified regions outside of loop 2 may participate in additional interactions with E2 of LRP5/6 and contribute to binding affinity.

Sclerostin also binds to the related LRP4 receptor. Despite its structural similarity with LRP5/6, LRP4 is not recognised as a Wnt co-receptor; instead, it is proposed to act as a sclerostin co-receptor since its overexpression enhances the efficacy of sclerostin in cell-based Wnt reporter assays whilst LRP4 silencing reduces sclerostin's function (Leupin et al. 2011). Mutations in LRP4 are found in patients with sclerosteosis 2 - another very rare high bone mass disorder that bears many similarities to those diseases in which sclerostin itself is lacking (Leupin et al. 2011, Fijalkowski et al. 2016). The causative mutations in the third propeller (E3) of LRP4 are associated with impaired sclerostin binding (Leupin et al. 2011). Interestingly, the failure of sclerostin to bind LRP4 - either through the presence of LRP4 high bone mass mutations or following administration of an antibody directed against LRP4 - is associated with increased serum sclerostin (Chang et al. 2014, Fijalkowski et al. 2016), suggesting LRP4 acts as an anchor to retain sclerostin in the skeleton. The ability of distinct sclerostin antibodies to differentially block binding to LRP4 and/or LRP6 has given some insights into the mechanism of the sclerostinLRP4 interaction and suggests that sclerostin loop 2 is not critical for binding LRP4 (Holdsworth et al. 2012, Gong et al. 2016).

Sclerostin was originally posited as potential modulator of BMP pathway signalling (Brunkow et al. 2001). Interactions between sclerostin and various BMP ligands, which result in diminished BMP receptor signalling have been reported (Winkler et al. 2003, Krause et al. 2010); however, these effects have not been extensively studied and do not appear to represent the principal actions of sclerostin on the skeleton so will not be discussed in depth here.

Structural studies of sclerostin revealed the presence of a heparin-binding patch, which is formed from a linear region of positively charged amino acids in loops 2 and 3, which covers one side of the protein and promotes a functional association between sclerostin and heparin that localises sclerostin to the surface of transfected cells (Veverka et al. 2009). More recently, this area was identified as a common binding region for various sulphated glycosaminoglycans (GAGs), which interfere with the interaction between sclerostin and LRP5/6 and restore WNT signalling in a reporter cell line (Salbach-Hirsch et al. 2015). GAGs are long unbranched polysaccharide molecules that are present as heparan sulphate proteoglycans within the extracellular matrix of bone. Hence, the binding of sclerostin to cell surface and bone matrix GAGs may contribute to the local regulation sclerostin function.

\section{Sclerostin inhibition of canonical WNT signalling}

The discovery that sclerostin bound the LRP5/6 WNT co-receptors to antagonise canonical WNT signalling came when the critical connection was made between the high bone mass (HBM) phenotype associated with the absence of sclerostin and similar phenotypes resulting from HBM mutations in LRP5 (Li et al. 2005, Semenov et al. 2005). The previously reported HBM mutations are all located in LRP5 E1 and helped identify the region of LRP5/6 to which sclerostin binds (Van Wesenbeeck et al. 2003, Little et al. 2017) since they impair sclerostin binding, thus preventing its action as a WNT inhibitor (Semenov \& He 2006). Subsequently, monoclonal antibodies which bind sclerostin and inhibit its interaction with LRP4/5/6 have been developed as a therapeutic strategy to increase bone mass and strength in osteoporosis and other low bone mass conditions. This topic is discussed in more depth later in this article, and has also been the subject of several recent reviews (Lovato \& Lewiecki 2017, McClung 2017, Canalis 2018).

\section{Cellular level actions of sclerostin revealed from in vitro and in vivo studies}

Since the discovery of sclerostin almost 20 years ago, a wealth of published data has described its actions at the cellular level, using in vitro model systems and in vivo studies. A range of approaches has been used, including sclerostin introduction (via treatment with recombinant sclerostin protein or overexpression of sclerostin in transgenic animals), sclerostin deletion (using animals null for the Sost gene) and neutralisation of endogenous sclerostin using Scl-Ab. The dual effects of sclerostin as a potent inhibitor of bone formation and a regulator of bone resorption have thereby emerged. Figure 3 summarises the cellular level actions of sclerostin, which are discussed in detail in the following sections. 


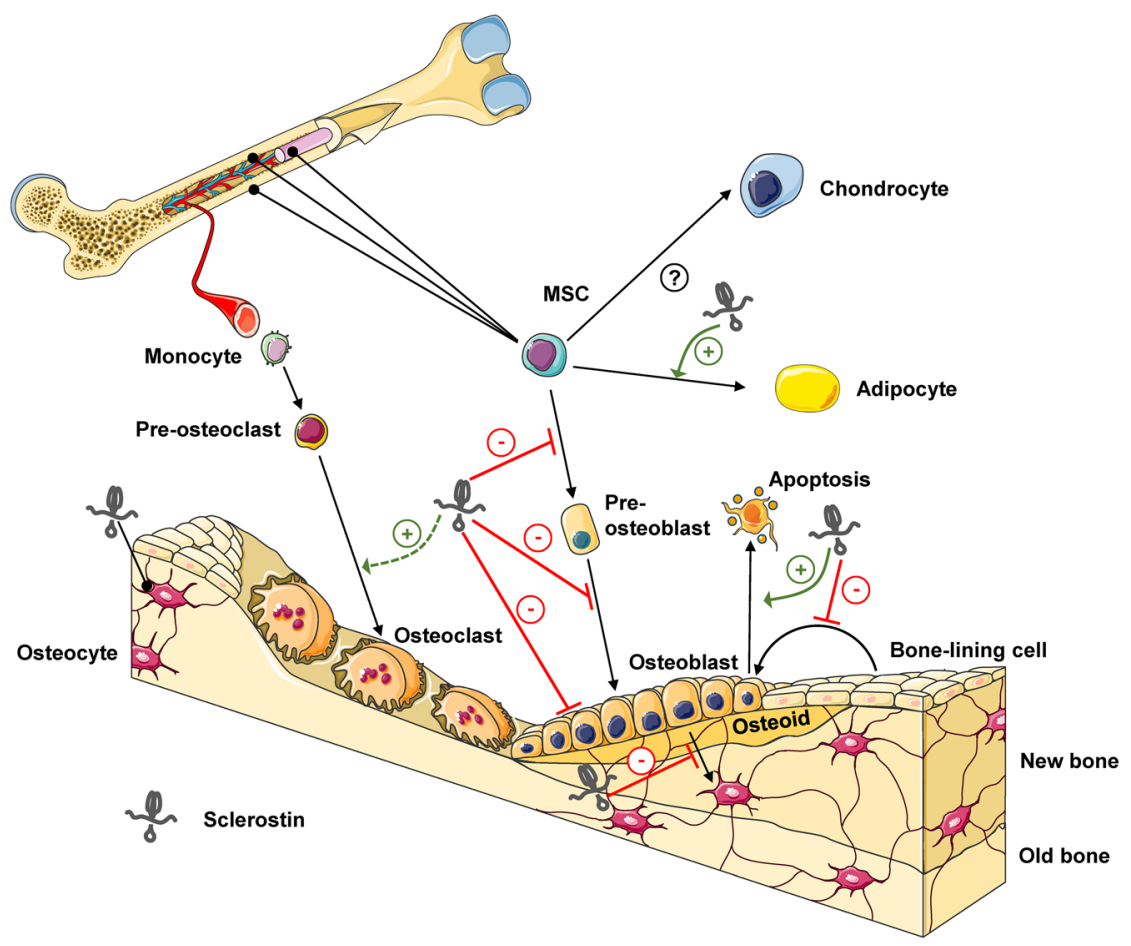

\section{Figure 3}

Effects of sclerostin on bone formation and resorption. Inhibition of canonical WNT signalling by sclerostin in inhibits bone formation. Sclerostin limits mesenchymal lineage cell differentiation towards the osteoblast lineage and promotes adipogenic differentiation, decreases bone matrix formation by osteoblasts, promotes osteoblast apoptosis, maintains bone lining cells in a quiescent state and inhibits differentiation of late osteoblasts into osteocytes. Sclerostin indirectly promotes bone resorption via control of the expression of osteoclast regulators by osteoblasts to enhancing osteoclast differentiation. This figure was produced using Servier Medical Art.

\section{Osteoblast lineage}

Sclerostin directly modulates the osteoprogenitor population and regulates osteoblast lineage function. The specific action of sclerostin as an inhibitor of canonical WNT signalling was demonstrated in the mouse preosteoblast cell lines transfected to express a luciferase reporter of the canonical WNT pathway (Veverka et al. 2009, Krause et al. 2010). In vitro, sclerostin inhibits cell proliferation, decreases alkaline phosphatase activity and mineralisation and increases apoptosis in osteogenic cultures of mouse and MSC or human primary osteoblasts (Winkler et al. 2003, Sutherland et al. 2004, Atkins et al. 2011). Likewise, alkaline phosphatase expression and mineralisation are reduced in ex vivo cultures of MSC or primary osteoblasts from transgenic mice engineered to overexpress sclerostin, compared with cells from WT littermate controls (Winkler et al. 2003, Yorgan et al. 2015). Conversely, inhibition of sclerostin is associated with restoration of WNT signalling, and cultures of MSCs collected from mice treated with Scl-Ab show enhanced osteogenesis compared with cells from control mice (Veverka et al. 2009, Shahnazari et al. 2012). The phosphate-regulating neutral endopeptidase, X-linked/ matrix extracellular phosphoglycoprotein (PHEX/ MEPE) axis is involved in regulating the mineralisation of newly formed bone. Sclerostin-mediated inhibition of osteoblast mineralisation in human primary cells or bovine bone explants is associated with upregulation of the mineralisation inhibitor MEPE and a concomitant decrease in expression of the pro-mineralisation enzyme PHEX (Atkins et al. 2011, Kogawa et al. 2018).

Insights into sclerostin's action as a regulator of osteoprogenitor differentiation, recruitment and mineral apposition have come from rodent studies using Scl-Ab. Lineage tracing experiments show that Scl-Ab increases the number of osteoprogenitor cells by increasing proliferation and decreasing apoptosis, thus indicating that sclerostin represses osteoprogenitor differentiation (Trinh et al. 2017). Neutralisation of sclerostin enhances proliferation and recruitment of osteoprogenitor cells to active surfaces, increases bone formation and osteoblast number and elevates 'osteoblast vigour', leading to increased bone formation per osteoblast (Ominsky et al. 2015, Taylor et al. 2016, Greenbaum et al. 2017, Boyce et al. 2018). The inactive surfaces of bone are occupied by bone lining cells (BLC), which arise from active osteoblasts that have neither undergone apoptosis nor embedded into newly mineralised matrix as osteocytes. Despite their abundance, these cells are a poorly studied population, and it has not yet been possible to culture BLC in vitro. Elegant in vivo lineage-tracing studies performed in mice highlighted BLC as a pool of precursors that are rapidly reactivated into active osteoblasts on periosteal and endocortical surfaces following treatment with Scl-Ab (Kim et al. 2017b), indicating that sclerostin inhibition of 
WNT signalling contributes to the maintenance of BLC in a quiescent state.

The transition of late osteoblasts to early osteocytes is inhibited in vitro by sclerostin, suggesting a role for sclerostin as a regulator of osteocyte maturation (Atkins et al. 2011). The study of sclerostin biology in osteocytes is challenging and the nature of the osteocyte means it is best studied as a cell within its lacuna, surrounded by its native 3D mineralised environment. Isolation and culture of primary osteocytes from bones is technically difficult and typically yields few viable cells, whilst the few immortalised osteocyte cell lines currently available show variable sclerostin expression. The early osteocyte cell lines, MLO-Y4 and MLO-A5 were derived from a transgenic mouse, which expressed large T-antigen under the control of the osteocalcin promoter (Kato et al. 1997, Kato et al. 2001). Sclerostin is a late osteocyte marker and is not highly expressed in MLO-Y4 and MLO-A5 cells. Two additional cell lines, IDG-SW3 and Ocy454, were isolated from double transgenic mice expressing green fluorescent protein $(G f p 1)$ under the dentin matrix acidic phosphoprotein 1 (Dmp1) promoter as well as a thermolabile large T-antigen. Importantly, both cell lines resemble late osteocytes and hence express high levels of late osteocyte markers, including sclerostin (Woo et al. 2011, Spatz et al. 2015). Ex vivo bone explants have the advantage of allowing the study of living osteocytes within their natural setting and are particularly well suited to investigating the response to mechanical loading (Kogawa et al. 2018, Morrell et al. 2018). More recently, advances have been made in the 3D culture of osteocytes using biomimetic assemblies, which allow formation of an inter-osteocyte connection network that replicates mechanostransduction responses (Sun et al. 2017, 2018). Since sclerostin expression is regulated by mechanical loading, access to such systems, which more faithfully reproduce the osteocyte's native environment, will prove highly useful in the future.

Sclerostin is a regulator of osteocyte apoptosis. In vivo, loss of Sost leads to enhanced canonical WNT signalling and decreased apoptosis in osteocytes (Lin et al. 2009, Krause et al. 2010). Focal radiation-induced DNA damage increases sclerostin expression in the locality of the irradiated area. Inhibition of sclerostin in a mouse model of radiation damage protected osteoblasts from apoptosis through activation of canonical WNT signalling (Chandra et al. 2017). The role of sclerostin in osteocyte apoptosis following exposure to glucocorticoids is less well understood and contrasting outcomes following the inhibition or absence of sclerostin have been reported.
In one mouse model, Scl-Ab prevented the decrease in lacunae occupancy and increase in osteocyte apoptosis caused by exogenous glucocorticoids (Achiou et al. 2015) whilst in a different model, genetic deletion of Sost did not reduce glucocorticoid-induced osteoblast/osteocyte apoptosis (Sato et al. 2016). These divergent outcomes may reflect differences in the models used, or the method of sclerostin inhibition, or could suggest that other factors besides sclerostin are involved in regulating osteocyte apoptosis.

The ability of osteocytes to resorb mineral in their locality is termed 'osteocytic osteolysis'. Although this remains a somewhat controversial topic, studies in lactating animals suggest that osteocytes may be able to remove the perilacunar matrix thereby mobilising calcium (reviewed by Qing \& Bonewald 2009, Prideaux et al. 2016, Kovacs 2017). Sclerostin has been reported to upregulate expression of several proteins involved in this process. Treatment of primary human osteocyte-like cells or mouse MLO-Y4 cells with sclerostin increased expression of transcripts encoding carbonic anhydrase 2 (Ca2), cathepsin $\mathrm{K}$ (Ctsk) and tartrate-resistant acid phosphatase form 5b (Acp5) in an LRP4/5/6-dependent manner whilst addition of sclerostin to ex vivo explant cultures of human cancellous bone increased lacunar size (Kogawa et al. 2013). Furthermore, studies conducted using bovine trabecular bone explants showed similar effects on expression of genes related to matrix catabolism and additionally demonstrated release of the C-terminal collagen telopeptide, $\beta$-CTx, which is indicative of collagen breakdown and is consistent with lacunar enlargement following exposure to recombinant sclerostin (Kogawa et al. 2018). Hence, sclerostin may contribute to the regulation of perilacunar mineral by resident osteocytes.

The importance of sclerostin in the maintenance of osteocyte morphology and connectivity is indicated from studies using genetic or antibody approaches. Mice lacking the matricellular protein periostin display increased sclerostin expression and round-shaped osteocytes with decreased dendrite number and length. Restoration of osteocyte morphology to a well-connected spindle-like morphology was observed when the Sost gene was deleted or Scl-Ab was used to neutralise sclerostin function (Ren et al. 2015). In other models, where osteocyte number (lacuna occupancy), morphology and connectivity are profoundly affected, including spinal cord injury and focal radiation-induced DNA damage, absence of sclerostin or Scl-Ab treatment preserved osteocyte number, morphology and orientation (Qin et al. 2015, Chandra et al. 2017). Interestingly, in models of 
mechanical unloading, expression of sclerostin is increased in individual osteocytes; however, the proportion of sclerostin-positive osteocytes is not changed (Lloyd et al. 2013) and inhibition of sclerostin by Scl-Ab does not alter osteocyte density (Qin et al. 2015).

Together, these findings indicate that the action of sclerostin as an inhibitor of bone formation is achieved throughout the osteoblast lineage: control of osteoprogenitor cell proliferation and recruitment, inhibition of osteogenic commitment and differentiation, negative regulation of osteoblast activity, maintenance of bone lining cell quiescence, suppression of late osteoblast differentiation into osteocytes and regulation of osteocyte longevity, shape and connectivity.

\section{Osteoclasts}

Whilst sclerostin does not appear to directly regulate the differentiation or activity of osteoclasts, studies of cells obtained from animals deficient in sclerostin or treated with Scl-Ab provide evidence that sclerostin does have important indirect effects on the osteoclast lineage. The binding of RANKL to its cognate receptor, receptor activator of nuclear factor-kB (RANK) on osteoclast precursors promotes osteoclastogenesis. RANKL activity is negatively regulated by the decoy receptor, OPG, hence the RANKL:OPG ratio is a key determinant of osteoclastogenesis. The importance of osteoblast-specific canonical WNT signalling on osteoclast differentiation has been demonstrated through manipulation of $\beta$-catenin in mice where osteoblast-specific pathway activation increased expression of the WNT target gene Opg, leading to reduced resorption whilst deletion of $\beta$-catenin in osteoblasts concomitantly decreased $\mathrm{Opg}$ expression and promoted higher resorption (Glass et al. 2005). Osteocytespecific activation of $\beta$-catenin also increased $O p g$, but in contrast to the effects in osteoblasts, Rankl expression and bone resorption were also increased. The increased Rankl expression was sclerostin-dependent since it was reversed by Scl-Ab whilst sclerostin overexpression in osteocytes enhanced Rankl expression in these cells (Tu et al. 2015). Therefore, inhibition of canonical WNT signalling by sclerostin in osteocytes would be expected to promote bone resorption.

Addition of recombinant sclerostin to in vitro cultures of the osteocyte MLO-Y4 cell line or human pre-osteocytes increased the RANKL:OPG ratio by upregulating Rankl expression and downregulating Opg. In co-cultures with mouse splenocytes or human PBMCs, sclerostin enhanced osteoclastogenesis and elevated resorption in a
RANKL-dependent manner; however, addition of sclerostin to splenocyte or PBMC monocultures had no effect on osteoclastogenesis, indicating that sclerostin does not directly influence these cells (Wijenayaka et al. 2011). Osteoblast lineage cells from rats treated with Scl-Ab show decreased RANKL:OPG ratio, largely as a result of elevated Opg expression (Taylor et al. 2016) and in agreement with this, fewer TRAP5b-positive osteoclastlike cells are obtained in cultures of osteoclast progenitors collected from rats following treatment with Scl-Ab (Stolina et al. 2014).

In addition to its effects on the RANKL:OPG ratio, there is evidence that sclerostin can affect the expression of other positive and negative regulators of osteoclastogenesis. Antibody-mediated sclerostin neutralisation in vivo decreased the abundance of mRNAs encoding colony stimulating factor 1 (Csf1) and increased WNT1-induced secreted protein 1 (Wisp1) abundance in osteoblastlineage cells (Taylor et al. 2016, Holdsworth et al. 2018), suggesting two potential additional indirect axes through which sclerostin could regulate osteoclastogenesis.

\section{Chondrocytes}

Differentiation of MSCs into chondrocytes is inhibited when canonical WNT signalling is activated. The effect of sclerostin on chondrocytes is relatively poorly studied; however, it is known that the protein is expressed by hypertrophic chondrocytes in the growth plate and by articular chondrocytes (Winkler et al. 2003, van Bezooijen et al. 2009, Chan et al. 2011). In vitro, sclerostin inhibits chondrocyte apoptosis and promotes a cartilage homeostatic phenotype by decreasing expression of catabolic proteases and increasing anabolic gene expression (Chan et al. 2011, Bouaziz et al. 2015). In vivo, sclerostin is expressed in the articular cartilage of rodents and humans; however, contradictory reports exist on the role of sclerostin in articular cartilage remodelling. Genetic loss of sclerostin (Sost KO) in mice does not alter articular cartilage formation, whilst its loss does appear to aggravate the development of osteoarthritis (OA) in mice subjected to joint instability (Bouaziz et al. 2015). Conversely, Roudier et al. (2013) reported that the absence of sclerostin does not alter the development of age-related $\mathrm{OA}$ in mice and that antibody-mediated neutralisation of sclerostin has no impact on cartilage remodelling in a rat model of post-traumatic OA. Interestingly, a recent report detailed the beneficial effect that exogenous sclerostin may have on the progression of post-traumatic OA. Indeed, Sost transgenic mice develop a less severe 
phenotype than WT or Sost KO mice, and intra-articular administration of recombinant sclerostin to WT mice reduces the level of activated MMPs (Chang et al. 2018). These reports highlight specific differences in the biology observed when considering the effect of genetic deletion/overexpression of sclerostin vs pharmacological inhibition.

\section{Adipocytes}

Adipose tissue exists in multiple anatomical locations, most of which are outside of the skeleton; however, bone has been shown to influence global energy metabolism through release of endocrine factors such as osteocalcin by osteoblast lineage cells (reviewed by Wei \& Karsenty 2015, Suchacki et al. 2017). The concept that sclerostin and energy metabolism could be linked reflects several observations including positive associations between serum sclerostin and metabolic parameters such as fat mass and type 2 diabetes (Amrein et al. 2012, Clarke \& Drake 2013). In addition, LRP5 HBM mutations have been linked with regulation of body fat distribution (Loh et al. 2015), highlighting the importance of canonical WNT pathway activity on adipose progenitors.

The three main types of adipose tissue - white adipose tissue (WAT), brown adipose tissue (BAT), bone marrow adipose tissue (BMAT) - reside in distinct anatomical locations and have non-overlapping physiological functions. WAT functions as an energy store and is the major component of the subcutaneous and visceral fat depots. Both WAT and BAT have an endocrine function and release adipokines, which regulate global energy metabolism. The primary role of BAT is thermoregulation; this adipose depot is found at low levels in adult and is characterised by expression of the uncoupling protein 1 transcript (Ucp1). Although BAT and WAT arise from different progenitors, WAT can gain expression of Ucp1 to become 'beige' adipose, which is functionally similar to BAT. BMAT is thought to arise from mesenchymal progenitors within the bone marrow cavity and is emerging as an additional active adipose depot that is functionally distinct from WAT and BAT and is highly linked to metabolic status and bone mass (Fairfield et al. 2017b).

Recent work performed in rodent models has identified a potential new role for sclerostin in adipose tissue regulation, as summarised in Figure 4. Consistent with the increase in circulating sclerostin in type 2 diabetes in humans, mice fed a high-fat diet display increased body weight and fat mass, develop metabolic

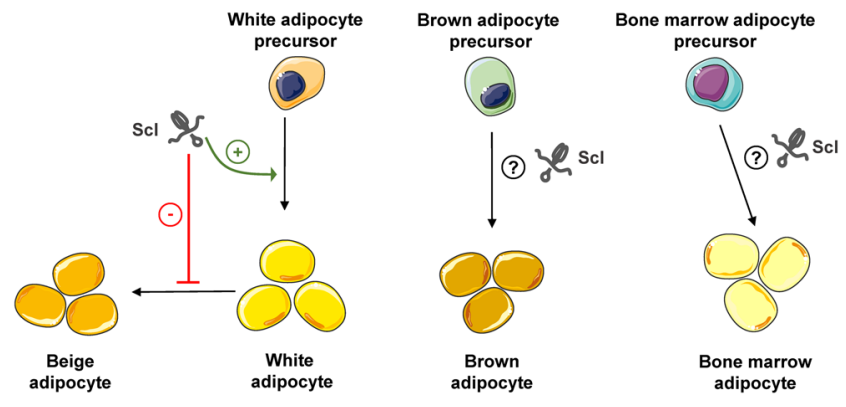

Figure 4

Summary of the emerging effects of sclerostin (Scl) on adipocytes. Sclerostin promotes differentiation of precursors into white adipocytes and negatively regulates browning of white adipocytes into beige adipocytes. The direct effects of sclerostin on brown adipocytes and bone marrow adipocytes are not currently understood. This figure was produced using Servier Medical Art.

disease and have elevated serum sclerostin (Kim et al. 2017a). In vitro, sclerostin inhibition of WNT signalling in MSCs or preadipocytes promotes adipogenesis whilst in vivo, Sost-null mice display reduced WAT that contains smaller adipocytes compared with WT littermate controls (Fairfield et al. 2017a, Kim et al. 2017a). In the same study, AAV-mediated sclerostin overexpression increased white adipose mass, in which WNT signalling was diminished compared with WAT from WT controls, whilst Scl-Ab partially reduced the weight gain and size of WAT deposits in mice fed a high-fat diet (Kim et al. 2017a). Together, these findings indicate that sclerostin neutralisation prevents accumulation of white adipose tissue mass. Sost-null mice exhibit increased expression of the beige marker, Ucp1, in WAT depots compared to WT littermates, suggesting sclerostin can regulate browning of white adipocytes. Interestingly, the amount of BAT in the interscapular depot did not differ in Sost-null mice compared with their WT littermates, which may reflect a lesser effect of sclerostin on constitutive brown adipose (Kim et al. 2017a).

Early in life, BMAT (also referred to as 'yellow marrow') starts to form in the bone marrow cavity. The extent of this adipose-rich tissue increases with age and its formation progresses from the extremities of the appendicular skeleton towards the centre of the body. The BMAT depot is less well understood than BAT or WAT, and its influence on the skeleton is the subject of intense interest since its anatomical location means it is ideally placed to provide a fat-bone connection. BMAT is elevated in conditions associated with low bone mass, including osteoporosis, anorexia nervosa, ageing and chronic kidney disease (CKD) (Hardouin et al. 2016, Fairfield et al . $2017 b$, Woods et al. 2018). In mice, absence of sclerostin 
is associated with decreased BMAT whilst Scl-Ab reduces BMAT accumulation by decreasing both adipocyte number and size (Fairfield et al. 2017b). In humans, the severity of CKD was recently reported to be associated with increases in both BMAT as well as serum sclerostin, which may suggest sclerostin contributes to BMAT in patients with CKD (Woods et al. 2018). Additional studies are required to investigate the role of sclerostin in BMAT regulation.

Sclerostin therefore participates in crosstalk between the skeleton and adipose tissue, acting as an endocrine factor to enhance adipogenesis in WAT and promote MSC differentiation towards the adipogenic lineage within bone marrow. Although the effect of LRP5 mutations on adipose progenitors and body fat distribution in humans has been reported, the translation of mutations affecting the SOST gene or sclerostin inhibition on adipogenesis and fat depot-specific regulation to humans is currently unknown.

\section{Sclerostin as a regulator of bone mass and strength}

The first preclinical evidence of sclerostin's negative effects on bone formation, mass and strength was reported using Sost transgenic mice that overexpress sclerostin. Reduced trabecular bone volume, cortical bone thickness, decreased bone strength due to significantly reduced bone formation and a non-significant change in bone resorption were observed in Sost transgenic mice compared with WT controls (Winkler et al. 2003). In contrast to the transgenic mice, Sost-knockout (KO) mice were shown to rapidly increase BMD in lumbar spine and long bones up to 4 months of age, after which lumbar spine BMD was maintained at the elevated level through 18 months of age, whilst there was a more gradual but continuous increase in long bone BMD in the same time frame (Ke et al. 2012). The bone phenotype in Sost KO mice reproduced the sclerosteosis phenotype as described above. Bone formation parameters were increased on trabecular, periosteal and endocortical surfaces, whilst no significant change was observed in serum markers of bone resorption or osteoclast surface area in the Sost KO mice compared with controls.

The results from these genetic manipulation studies in mice confirmed that sclerostin is indeed a negative regulator of bone mass and bone strength via the inhibition of bone formation in vivo. These data led to the hypothesis that pharmacological inhibition of sclerostin may deliver benefit to patients suffering from conditions of low bone mass and increased risk of fragility fractures, such as osteoporosis, through the induction of an increase in bone formation, mass and strength. Several Scl-Abs have been generated and tested for their efficacy in preclinical models and in patients with low bone mass and/or poor bone quality. It appears that the bone formation response to Scl-Ab treatment can be separated into two phases: an initial transient phase and a steady phase that persists with longer-term treatment. During the transient phase, Scl-Ab significantly and rapidly increases modelling-based bone formation by activating bone lining cells to become bone-forming osteoblasts, increasing osteoblast activity and recruitment and reducing osteoblast apoptosis (Ominsky et al. 2017a). However, after the transient phase, bone formation returns towards the baseline level despite continuous treatment with Scl-Ab. The mechanism for this steady phase effect on bone formation is a topic of continued investigation. A rapid increase in bone mass during the transient phase may lead to a reduction in local micro-strain on bone surface, thus activating negative feedback mechanisms to control bone formation. Upregulation of WNT antagonists including sclerostin and DKK1 and normalisation of some WNT target genes may contribute to the self-regulation of bone formation during the steady phase of treatment (Taylor et al. 2016, Holdsworth et al. 2018). During the steady phase, Scl-Ab increased wall thickness and decreased resorption depth leading to a positive bone balance in the remodelling unit (Boyce et al. 2017). As mentioned above, Scl-Ab treatment also reduces osteocyte apoptosis and restores osteocyte morphology and connectivity in disease models that affect osteocytes (Achiou et al. 2015, Qin et al. 2015, Ren et al. 2015), although the contribution of these effects on bone formation and resorption requires further investigation. While the effect of Scl-Ab on bone resorption in preclinical models has been either no significant change or significant decrease, depending on the baseline bone resorption activities (see review by Ominsky et al. 2017a), results from clinical trials have consistently demonstrated that Scl-Ab significantly decreased serum markers of bone resorption during the transient phase and maintained at the decreased level in the steady phase (McClung et al. 2014, Cosman et al. 2016). Histomorphometric analysis of bone biopsies from clinical trials of Scl-Ab indicates that sclerostin inhibition produces an early, significant bone-forming effect and a sustained reduction in bone resorption (Chavassieux et al. 2017).

Studies in rodent models have permitted the comparison of tissue-level outcomes following antibodymediated inhibition of sclerostin, as well as genetic deletion or transgenic overexpression of Sost, and 
overexpression of recombinant sclerostin by the liver. Table 1 summarises these findings.

The rapid bone gain induced by Scl-Ab treatment leads to a significant increase in bone strength while maintaining bone quality in the osteoporosis animal models of OVX rats and OVX cynomolgus monkeys with 12 months of treatment (Ominsky et al. 2017a,b). The clinical translation of these preclinical data has been demonstrated in postmenopausal osteoporosis, osteoporosis in men and other conditions with low bone mass and poor bone quality. Much of the clinical data have come from trials of Scl-Ab in patients with osteoporosis and are summarised in several recent reviews (Lovato \& Lewiecki 2017, McClung 2017, Canalis 2018).

The data from preclinical animal studies as well as clinical trials in patients with low bone mass and increased risk of fragility fracture confirm that sclerostin is a negative regulator of bone formation, bone mass and bone strength. Experimental data also show that inhibition of sclerostin with Scl-Ab stimulates bone formation, decreases bone resorption, increases bone mass and strength and reduces the risk of fragility fractures.

\section{The involvement of sclerostin in other human disease: multiple myeloma}

Multiple myeloma (MM) is a plasma cell (differentiated B lymphocyte) cancer, characterised by extensive proliferation of transformed cells in the bone marrow. Bone disease is a devastating complication of MM caused by a deregulation of the cellular determinants of bone homeostasis, resulting in bone loss, osteolytic lesions, bone pain and increased fracture risk (Hameed et al. 2014). WNT signalling has been associated with MM through the identification of the WNT antagonist DKK1 as a potential mediator of molecular crosstalk between MM cells and osteoblasts (Tian et al. 2003). In addition to KK1, sclerostin has also been implicated in MM where patients with active myeloma display increased levels of circulating sclerostin, which correlates with severe bone disease (Terpos et al. 2012). Recently, it has been reported that DKK1 and sclerostin may be early markers of relapse in $\mathrm{MM}$, as a significant increase in serum concentrations of both proteins are observed prior to relapse (Mabille et al. 2018).

The source of sclerostin in MM is controversial, with several publications claiming expression and secretion from MM cells (Brunetti et al. 2011, Colucci et al. 2011, Habibi et al. 2013, Wang et al. 2014). Conversely, a study detailing the expression profile in a cohort of $630 \mathrm{MM}$ patients described no difference in $\mathrm{MM}$ bone marrow plasma cell expression of SOST compared to healthy controls (McDonald et al. 2017). Perhaps a more plausible mechanism to explain the elevated sclerostin in MM patients reflects interaction of the MM tumour directly with bone cells in the tumour microenvironment. Indeed, it has been reported that osteocytes in contact with MM cells express high levels of sclerostin in vitro (Delgado-Calle et al. 2016). This subsequently causes a downregulation of local WNT signalling and inhibition of osteoblast differentiation. Sclerostin expression is evident in marrow stromal cells and osteoblasts within MM patient bone marrow samples, and MM cells can induce sclerostin expression in immature osteoblasts in vitro, which has the capacity to subsequently inhibit osteoblast differentiation. Interestingly, expression of Sost appears to be regulated by MM cell-derived DKK1 (Eda et al. 2016). MM cells also appear to increase the number of sclerostin-positive osteocytes in cortical and trabecular bone in murine models (Delgado-Calle et al. 2017), thus giving rise to another potential explanation for elevated circulating sclerostin in MM patients.

Consequently, sclerostin has become a pharmacological target in $\mathrm{MM}$ research. In preclinical murine models, treatment with Scl-Ab antibody reversed myeloma bone disease through induction of

Table 1 Summary of bone tissue-level outcomes associated with sclerostin intervention in rodent models.

\begin{tabular}{lcc} 
& & Bone mass \\
\cline { 1 - 2 } null & $\uparrow \uparrow \uparrow$ \\
Scl-Ab & $\uparrow \uparrow$ \\
Sost transgenic & $\downarrow \downarrow$ \\
Scl overexpression & $\downarrow$
\end{tabular}

\begin{tabular}{c}
\hline Bone formation \\
\hline$\uparrow \uparrow \uparrow$ \\
$\uparrow \uparrow$ \\
$\downarrow \downarrow$ \\
- \\
\hline
\end{tabular}

\begin{tabular}{c} 
Bone resorption \\
\hline- \\
$\downarrow /-$ \\
-
\end{tabular}

\begin{tabular}{l} 
References \\
\hline Li et al. (2008) \\
Ke et al. (2012) \\
Ke et al. (2012) \\
Zhang et al. (2016), Kim et al. (2017a)
\end{tabular}

The column titled 'Bone mass' refers to trabecular BV/TV in the axial (spine) or appendicular (tibia or femur) skeleton. The column titled 'Bone formation' refers to serum bone turnover markers indicative of bone formation. The column titled 'Bone resorption' refers to serum bone turnover markers indicative of bone resorption. The symbols $\uparrow$ or $\downarrow$ indicate an increase, or decrease, in this parameter, respectively, and the number of arrows reflecting the size of the effect; - indicates no change in this parameter.

NR, not reported.

https://jme.bioscientifica.com

https://doi.org/10.1530/JME-18-0176 (c) 2019 Society for Endocrinology Published by Bioscientifica Ltd. Printed in Great Britain 
osteoblastogenesis and suppression of, or no effect on, osteoclast formation (depending on the antibody used). Interestingly, treatment with $\mathrm{Scl}-\mathrm{Ab}$ does not appear to directly affect MM cells either in vitro or in vivo (Eda et al. 2016, Delgado-Calle et al. 2017, McDonald et al. 2017).

\section{Future horizons}

The discovery of causative mutations in the SOST gene in patients with sclerosteosis identified sclerostin as a 'gem from the genome' with a critical role in bone homeostasis (Paszty et al. 2010). Significant advances have been made in understanding the expression, biochemical and structural features of sclerostin. There are aspects of the biochemistry of this small secreted glycoprotein, which lend themselves to further investigation, for example, the biological relevance of sclerostin glycosylation, and definition of the epitope(s) through which sclerostin binds LRP4. The discovery that this protein acts as an inhibitor of the canonical WNT signalling cascade illuminated the way it regulates bone metabolism, indicating that sclerostin plays a critical role in controlling bone formation and may play an indirect role in stimulating bone resorption. Thus, pharmacological inhibition of sclerostin with Scl-Ab increases bone formation and decreases bone resorption, leading to increased bone mass and strength. However, questions remain. The relationship between circulating sclerostin and bone formation is not simple and the significance of systemic sclerostin on skeletal homeostasis is far from clear, hence further exploration of this topic is required. Although it is expressed in vascular smooth muscle cells within the aorta, the absence or inhibition of sclerostin in preclinical studies has not been linked to changes in vascular calcification and sclerostin's role in the vasculature is not well understood. As discussed in a recent review (Appelman-Dijkstra 2018), the imbalance in serious adjudicated cardiovascular events that was observed in one of two large phase III studies with Scl-Ab in postmenopausal women with osteoporosis (Cosman et al. 2016, Saag et al. 2017) highlights the need to better understand the role of sclerostin in the vascular system.

In addition to providing structural support for the body and protection for internal organs, the skeleton is now known to influence other complex biological processes, including regulation of energy metabolism. The emerging role of sclerostin as a regulator of adipose depots points towards the existence of additional biological axes for sclerostin. In contrast to the local function of sclerostin as an inhibitor of bone formation, new findings in rodent models suggest two additional roles for sclerostin: as a local regulator of MSC fate which promotes bone marrow adipose, and as an osteocyte-secreted endocrine molecule, linking the bone with anatomically distant adipose tissue. The translation to human is currently unknown and further studies are required to more completely elucidate the bone-adipose relationship(s) and their contribution to bone mass and strength. Finally, new investigations into the role of sclerostin in multiple myeloma bone disease have suggested that sclerostin inhibition could be beneficial in this setting and have provided a platform for further studies.

Declaration of interest

All authors have been employees of UCB Pharma and may hold UCB Pharma shares and/or stock options.

\section{Funding}

This work did not receive any specific grant from any funding agency in the public, commercial, or not-for-profit sector.

\section{Acknowledgements}

The authors thank the romosozumab teams at UCB Pharma and Amgen Inc. for their support.

\section{References}

Achiou Z, Toumi H, Touvier J, Boudenot A, Uzbekov R, Ominsky MS, Pallu S \& Lespessailles E 2015 Sclerostin antibody and interval treadmill training effects in a rodent model of glucocorticoidinduced osteopenia. Bone 81 691-701. (https://doi.org/10.1016/j. bone.2015.09.010)

Amrein K, Amrein S, Drexler C, Dimai HP, Dobnig H, Pfeifer K, Tomaschitz A, Pieber TR \& Fahrleitner-Pammer A 2012 Sclerostin and its association with physical activity, age, gender, body composition, and bone mineral content in healthy adults. Journal of Clinical Endocrinology and Metabolism 97 148-154. (https://doi. org/10.1210/jc.2011-2152)

Appelman-Dijkstra NM \& Papapoulos SE 2018 Clinical advantages and disadvantages of anabolic bone therapies targeting the WNT pathway. Nature Reviews Endocrinology Epub. (https://doi.org/10.1038/ s41574-018-0087-0)

Atkins GJ, Rowe PS, Lim HP, Welldon KJ, Ormsby R, Wijenayaka AR, Zelenchuk L, Evdokiou A \& Findlay DM 2011 Sclerostin is a locally acting regulator of late-osteoblast/preosteocyte differentiation and regulates mineralization through a MEPE-ASARM-dependent mechanism. Journal of Bone and Mineral Research 26 1425-1436. (https://doi.org/10.1002/jbmr.345)

Balemans W, Van Den Ende J, Freire Paes-Alves A, Dikkers FG, Willems PJ, Vanhoenacker F, de Almeida-Melo N, Alves CF, Stratakis CA, Hill SC, et al. 1999 Localization of the gene for sclerosteosis to the van Buchem disease-gene region on chromosome 17q12-q21. American Journal of Human Genetics 64 1661-1669. (https://doi.org/10.1086/302416)

Balemans W, Ebeling M, Patel N, Van Hul E, Olson P, Dioszegi M, Lacza C, Wuyts W, Van Den Ende J, Willems P, et al. 2001 Increased 
bone density in sclerosteosis is due to the deficiency of a novel secreted protein (SOST). Human Molecular Genetics 10 537-543. (https://doi.org/10.1093/hmg/10.5.537)

Balemans W, Patel N, Ebeling M, Van Hul E, Wuyts W, Lacza C, Dioszegi M, Dikkers FG, Hildering P, Willems PJ, et al. 2002 Identification of a $52 \mathrm{~kb}$ deletion downstream of the SOST gene in patients with van Buchem disease. Journal of Medical Genetics 39 91-97. (https://doi.org/10.1136/jmg.39.2.91)

Baron R \& Kneissel M 2013 WNT signaling in bone homeostasis and disease: from human mutations to treatments. Nature Medicine 19 179-192. (https://doi.org/10.1038/nm.3074)

Beighton P, Barnard A, Hamersma H \& van der Wouden A 1984 The syndromic status of sclerosteosis and van Buchem disease. Clinical Genetics 25 175-181. (https://doi.org/10.1111/j.1399-0004.1984. tb00481.x)

Boskey AL \& Imbert L 2017 Bone quality changes associated with aging and disease: a review. Annals of the New York Academy of Sciences 1410 93-106. (https://doi.org/10.1111/nyas.13572)

Bouaziz W, Funck-Brentano T, Lin H, Marty C, Ea HK, Hay E \& CohenSolal M 2015 Loss of sclerostin promotes osteoarthritis in mice via beta-catenin-dependent and -independent Wnt pathways. Arthritis Research and Therapy 17 24. (https://doi.org/10.1186/s13075-0150540-6)

Bourhis E, Tam C, Franke Y, Bazan JF, Ernst J, Hwang J, Costa M, Cochran AG \& Hannoush RN 2010 Reconstitution of a frizzled8. Wnt3a.LRP6 signaling complex reveals multiple Wnt and Dkk1 binding sites on LRP6. Journal of Biological Chemistry 285 9172-9179. (https://doi.org/10.1074/jbc.M109.092130)

Bourhis E, Wang W, Tam C, Hwang J, Zhang Y, Spittler D, Huang OW, Gong Y, Estevez A, Zilberleyb I, et al. 2011 Wnt antagonists bind through a short peptide to the first beta-propeller domain of LRP5/6. Structure 19 1433-1442. (https://doi.org/10.1016/j.str.2011.07.005)

Boyce RW, Niu QT \& Ominsky MS 2017 Kinetic reconstruction reveals time-dependent effects of romosozumab on bone formation and osteoblast function in vertebral cancellous and cortical bone in cynomolgus monkeys. Bone 101 77-87. (https://doi.org/10.1016/j. bone.2017.04.005)

Boyce RW, Brown D, Felx M, Mellal N, Locher K, Pyrah I, Ominsky MS \& Taylor S 2018 Decreased osteoprogenitor proliferation precedes attenuation of cancellous bone formation in ovariectomized rats treated with sclerostin antibody. Bone Reports 8 90-94. (https://doi. org/10.1016/j.bonr.2018.03.001)

Brunetti G, Oranger A, Mori G, Specchia G, Rinaldi E, Curci P, Zallone A, Rizzi R, Grano M \& Colucci S 2011 Sclerostin is overexpressed by plasma cells from multiple myeloma patients. Annals of the New York Academy of Sciences 1237 19-23. (https://doi. org/10.1111/j.1749-6632.2011.06196.x)

Brunkow ME, Gardner JC, Van Ness J, Paeper BW, Kovacevich BR, Proll S, Skonier JE, Zhao L, Sabo PJ, Fu Y, et al. 2001 Bone dysplasia sclerosteosis results from loss of the SOST gene product, a novel cystine knot-containing protein. American Journal of Human Genetics 68 577-589. (https://doi.org/10.1086/318811)

Canalis E 2018 MANAGEMENT OF ENDOCRINE DISEASE: novel anabolic treatments for osteoporosis. European Journal of Endocrinology 178 R33-R44. (https://doi.org/10.1530/EJE-17-0920)

Chan BY, Fuller ES, Russell AK, Smith SM, Smith MM, Jackson MT, Cake MA, Read RA, Bateman JF, Sambrook PN, et al. 2011 Increased chondrocyte sclerostin may protect against cartilage degradation in osteoarthritis. Osteoarthritis and Cartilage 19 874-885. (https://doi. org/10.1016/j.joca.2011.04.014)

Chan WCW, Tsang KY, Cheng YW, Ng VCW, Chik H, Tan ZJ, BootHandford R, Boyde A, Cheung KMC, Cheah KSE, et al. 2017 Activating the unfolded protein response in osteocytes causes hyperostosis consistent with craniodiaphyseal dysplasia. Human Molecular Genetics 26 4572-4587. (https://doi.org/10.1093/hmg/ ddx339)
Chandra A, Lin T, Young T, Tong W, Ma X, Tseng WJ, Kramer I, Kneissel M, Levine MA, Zhang Y, et al. 2017 Suppression of sclerostin alleviates radiation-induced bone loss by protecting bone-forming cells and their progenitors through distinct mechanisms. Journal of Bone and Mineral Research 32 360-372. (https://doi.org/10.1002/ jbmr.2996)

Chang MK, Kramer I, Huber T, Kinzel B, Guth-Gundel S, Leupin O \& Kneissel M 2014 Disruption of Lrp4 function by genetic deletion or pharmacological blockade increases bone mass and serum sclerostin levels. PNAS 111 E5187-E5195. (https://doi.org/10.1073/ pnas.1413828111)

Chang JC, Christiansen BA, Murugesh DK, Sebastian A, Hum NR, Collette NM, Hatsell S, Economides AN, Blanchette CD \& Loots GG 2018 SOST/sclerostin improves posttraumatic osteoarthritis and inhibits MMP2/3 expression after injury. Journal of Bone and Mineral Research 33 1105-1113. (https://doi.org/10.1002/jbmr.3397)

Chavassieux P, Chapurlat R, Portero-Muzy N, Garcia P, Brown JP, Horlait S, Libanati C, Boyce R, Wang A \& Grauer A 2017 Effects of romosozumab in postmenopausal women with osteoporosis after 2 and 12 months: bone histomorphometry substudy. Journal of Bone and Mineral Research 32 ABSTRACT 1072. (https://doi.org/10.1002/ jbmr.3063)

Chouinard L, Felx M, Mellal N, Varela A, Mann P, Jolette J, Samadfam R, Smith SY, Locher K, Buntich S, et al. 2016 Carcinogenicity risk assessment of romosozumab: a review of scientific weight-ofevidence and findings in a rat lifetime pharmacology study. Regulatory Toxicology and Pharmacology 81 212-222. (https://doi. org/10.1016/j.yrtph.2016.08.010)

Clarke BL \& Drake MT 2013 Clinical utility of serum sclerostin measurements. Bonekey Reports 2361.

Collette NM, Yee CS, Hum NR, Murugesh DK, Christiansen BA, Xie L, Economides AN, Manilay JO, Robling AG \& Loots GG 2016 Sostdc1 deficiency accelerates fracture healing by promoting the expansion of periosteal mesenchymal stem cells. Bone 88 20-30. (https://doi. org/10.1016/j.bone.2016.04.005)

Colucci S, Brunetti G, Oranger A, Mori G, Sardone F, Specchia G, Rinaldi E, Curci P, Liso V, Passeri G, et al. 2011 Myeloma cells suppress osteoblasts through sclerostin secretion. Blood Cancer Journal 1 e27. (https://doi.org/10.1038/bcj.2011.22)

Cooper C \& Ferrari SL 2017 IOF Compendium of Osteoporosis.

Cosman F, Crittenden DB, Adachi JD, Binkley N, Czerwinski E, Ferrari S, Hofbauer LC, Lau E, Lewiecki EM, Miyauchi A, et al. 2016 Romosozumab treatment in postmenopausal women with osteoporosis. New England Journal of Medicine 375 1532-1543. (https://doi.org/10.1056/NEJMoa1607948)

Delgado-Calle J, Anderson J, Cregor MD, Hiasa M, Chirgwin JM, Carlesso N, Yoneda T, Mohammad KS, Plotkin LI, Roodman GD, et al. 2016 Bidirectional notch signaling and osteocyte-derived factors in the bone marrow microenvironment promote tumor cell proliferation and bone destruction in multiple myeloma. Cancer Research 76 1089-1100. (https://doi.org/10.1158/0008-5472.CAN-151703)

Delgado-Calle J, Anderson J, Cregor MD, Condon KW, Kuhstoss SA, Plotkin LI, Bellido T \& Roodman GD 2017 Genetic deletion of Sost or pharmacological inhibition of sclerostin prevent multiple myeloma-induced bone disease without affecting tumor growth. Leukemia 31 2686-2694. (https://doi.org/10.1038/leu.2017.152)

Didangelos A, Yin X, Mandal K, Baumert M, Jahangiri M \& Mayr M 2010 Proteomics characterization of extracellular space components in the human aorta. Molecular and Cellular Proteomics 9 2048-2062. (https://doi.org/10.1074/mcp.M110.001693)

Eda H, Santo L, Wein MN, Hu DZ, Cirstea DD, Nemani N, Tai YT, Raines SE, Kuhstoss SA, Munshi NC, et al. 2016 Regulation of sclerostin expression in multiple myeloma by Dkk-1: a potential therapeutic strategy for myeloma bone disease. Journal of Bone and Mineral Research 31 1225-1234. (https://doi.org/10.1002/jbmr.2789) 
Ettenberg SA, Charlat O, Daley MP, Liu S, Vincent KJ, Stuart DD, Schuller AG, Yuan J, Ospina B, Green J, et al. 2010 Inhibition of tumorigenesis driven by different Wnt proteins requires blockade of distinct ligand-binding regions by LRP6 antibodies. PNAS $\mathbf{1 0 7}$ 15473-15478. (https://doi.org/10.1073/pnas.1007428107)

Fairfield H, Falank C, Harris E, Demambro V, McDonald M, Pettitt JA, Mohanty ST, Croucher P, Kramer I, Kneissel M, et al. 2017a The skeletal cell-derived molecule sclerostin drives bone marrow adipogenesis. Journal of Cellular Physiology 233 1156-1167. (https:// doi.org/10.1002/jcp.25976)

Fairfield H, Rosen CJ \& Reagan MR 2017b Connecting bone and fat: the potential role for sclerostin. Current Molecular Biology Reports 3 114-121. (https://doi.org/10.1007/s40610-017-0057-7)

Fijalkowski I, Geets E, Steenackers E, Van Hoof V, Ramos FJ, Mortier G, Fortuna AM, Van Hul W \& Boudin E 2016 A novel domain-specific mutation in a sclerosteosis patient suggests a role of LRP4 as an anchor for sclerostin in human bone. Journal of Bone and Mineral Research 31 874-881. (https://doi.org/10.1002/jbmr.2782)

Glass DA 2nd, Bialek P, Ahn JD, Starbuck M, Patel MS, Clevers H, Taketo MM, Long F, McMahon AP, Lang RA, et al. 2005 Canonical Wnt signaling in differentiated osteoblasts controls osteoclast differentiation. Developmental Cell 8 751-764. (https://doi. org/10.1016/j.devcel.2005.02.017)

Gong Y, Slee RB, Fukai N, Rawadi G, Roman-Roman S, Reginato AM, Wang H, Cundy T, Glorieux FH, Lev D, et al. 2001 LDL receptorrelated protein 5 (LRP5) affects bone accrual and eye development. Cell 107 513-523. (https://doi.org/10.1016/S0092-8674(01)00571-2)

Gong J, Cao J, Ho J, Chen C \& Paszty C 2016 MO0300 Romosozumab blocks the binding of sclerostin to the two key Wnt signaling co-receptors, LRP5 and LRP6, but not to LRP4. Journal of Bone and Mineral Research $\mathbf{3 1}$ Supplement 1.

Greenbaum A, Chan KY, Dobreva T, Brown D, Balani DH, Boyce R, Kronenberg HM, McBride HJ \& Gradinaru V 2017 Bone CLARITY: clearing, imaging, and computational analysis of osteoprogenitors within intact bone marrow. Science Translational Medicine 9 eaah6518. (https://doi.org/10.1126/scitranslmed.aah6518)

Habibi H, Abroun S, Hajifathali A, Soleimani M, Kaviani S, Kalantari N \& Eslahchi S 2013 Osteogenic inhibition in multiple myeloma. Cell Journal 15 266-271.

Hameed A, Brady JJ, Dowling P, Clynes M \& O'Gorman P 2014 Bone disease in multiple myeloma: pathophysiology and management. Cancer Growth Metastasis 7 33-42. (https://doi.org/10.4137/CGM. S16817)

Hardouin P, Rharass T \& Lucas S 2016 Bone marrow adipose tissue: to be or not to be a typical adipose tissue? Frontiers in Endocrinology $\mathbf{7} 85$.

Hessvik NP \& Llorente A 2018 Current knowledge on exosome biogenesis and release. Cellular and Molecular Life Sciences $\mathbf{7 5}$ 193-208. (https://doi.org/10.1007/s00018-017-2595-9)

Holdsworth G, Slocombe P, Doyle C, Sweeney B, Veverka V, Le Riche K, Franklin RJ, Compson J, Brookings D, Turner J, et al. 2012 Characterization of the interaction of sclerostin with the low density lipoprotein receptor-related protein (LRP) family of Wnt co-receptors. Journal of Biological Chemistry 287 26464-26477. (https://doi.org/10.1074/jbc.M112.350108)

Holdsworth G, Greenslade K, Jose J, Stencel Z, Kirby H, Moore A, Ke HZ \& Robinson MK 2018 Dampening of the bone formation response following repeat dosing with sclerostin antibody in mice is associated with up-regulation of Wnt antagonists. Bone 107 93-103. (https://doi.org/10.1016/j.bone.2017.11.003)

Kato Y, Windle JJ, Koop BA, Mundy GR \& Bonewald LF 1997 Establishment of an osteocyte-like cell line, MLO-Y4. Journal of Bone and Mineral Research 12 2014-2023. (https://doi.org/10.1359/ jbmr.1997.12.12.2014)

Kato Y, Boskey A, Spevak L, Dallas M, Hori M \& Bonewald LF 2001 Establishment of an osteoid preosteocyte-like cell MLO-A5 that spontaneously mineralizes in culture. Journal of Bone and Mineral
Research 16 1622-1633. (https://doi.org/10.1359/ jbmr.2001.16.9.1622)

Ke HZ, Richards WG, Li X \& Ominsky MS 2012 Sclerostin and Dickkopf-1 as therapeutic targets in bone diseases. Endocrine Reviews 33 747-783. (https://doi.org/10.1210/er.2011-1060)

Kim SJ, Bieganski T, Sohn YB, Kozlowski K, Semenov M, Okamoto N, Kim CH, Ko AR, Ahn GH, Choi YL, et al. 2011 Identification of signal peptide domain SOST mutations in autosomal dominant craniodiaphyseal dysplasia. Human Genetics 129 497-502. (https:// doi.org/10.1007/s00439-011-0947-3)

Kim SP, Frey JL, Li Z, Kushwaha P, Zoch ML, Tomlinson RE, Da H, Aja S, Noh HL, Kim JK, et al. 2017a Sclerostin influences body composition by regulating catabolic and anabolic metabolism in adipocytes. PNAS 114 E11238-E11247. (https://doi.org/10.1073/pnas.1707876115)

Kim SW, Lu Y, Williams EA, Lai F, Lee JY, Enishi T, Balani DH, Ominsky MS, Ke HZ, Kronenberg HM, et al. 2017b Sclerostin antibody administration converts bone lining cells into active osteoblasts. Journal of Bone and Mineral Research 32 892-901. (https:// doi.org/10.1002/jbmr.3038)

Kogawa M, Wijenayaka AR, Ormsby RT, Thomas GP, Anderson PH, Bonewald LF, Findlay DM \& Atkins GJ 2013 Sclerostin regulates release of bone mineral by osteocytes by induction of carbonic anhydrase 2. Journal of Bone and Mineral Research 28 2436-2448. (https://doi.org/10.1002/jbmr.2003)

Kogawa M, Khalid KA, Wijenayaka AR, Ormsby RT, Evdokiou A, Anderson PH, Findlay DM \& Atkins GJ 2018 Recombinant sclerostin antagonizes effects of ex vivo mechanical loading in trabecular bone and increases osteocyte lacunar size. American Journal of PhysiologyCell Physiology 314 C53-C61. (https://doi.org/10.1152/ ajpcell.00175.2017)

Kovacs CS 2017 The skeleton is a storehouse of Mineral that is plundered during lactation and (fully?) replenished afterwards. Journal of Bone and Mineral Research 32 676-680. (https://doi. org/10.1002/jbmr.3090)

Krause C, Korchynskyi O, de Rooij K, Weidauer SE, de Gorter DJ, van Bezooijen RL, Hatsell S, Economides AN, Mueller TD, Lowik CW, et al. 2010 Distinct modes of inhibition by sclerostin on bone morphogenetic protein and Wnt signaling pathways. Journal of Biological Chemistry 285 41614-41626. (https://doi.org/10.1074/jbc. M110.153890)

Krishna SM, Seto SW, Jose RJ, Li J, Morton SK, Biros E, Wang Y, Nsengiyumva V, Lindeman JH, Loots GG, et al. 2017 Wnt signaling pathway inhibitor sclerostin inhibits angiotensin II-induced aortic aneurysm and atherosclerosis. Arteriosclerosis, Thrombosis, and Vascular Biology 37 553-566. (https://doi.org/10.1161/ ATVBAHA.116.308723)

Lerner UH \& Ohlsson C 2015 The WNT system: background and its role in bone. Journal of Internal Medicine 277 630-649. (https://doi. org/10.1111/joim.12368)

Leupin O, Piters E, Halleux C, Hu S, Kramer I, Morvan F, Bouwmeester T, Schirle M, Bueno-Lozano M, Fuentes FJ, et al. 2011 Bone overgrowthassociated mutations in the LRP4 gene impair sclerostin facilitator function. Journal of Biological Chemistry 286 19489-19500. (https:// doi.org/10.1074/jbc.M110.190330)

Li X, Zhang Y, Kang H, Liu W, Liu P, Zhang J, Harris SE \& Wu D 2005 Sclerostin binds to LRP5/6 and antagonizes canonical Wnt signaling. Journal of Biological Chemistry 280 19883-19887. (https://doi. org/10.1074/jbc.M413274200)

Li X, Ominsky MS, Niu QT, Sun N, Daugherty B, D'Agostin D, Kurahara C, Gao Y, Cao J, Gong J et al. 2008 Targeted deletion of the sclerostin gene in mice results in increased bone formation and bone strength. Journal of Bone and Mineral Research 23 860-869. (https:// doi.org/10.1359/jbmr.080216)

Lin C, Jiang X, Dai Z, Guo X, Weng T, Wang J, Li Y, Feng G, Gao X \& He L 2009 Sclerostin mediates bone response to mechanical unloading through antagonizing Wnt/beta-catenin signaling. Journal 
of Bone and Mineral Research 24 1651-1661. (https://doi.org/10.1359/ jbmr.090411)

Little DG, Peacock L, Mikulec K, Kneissel M, Kramer I, Cheng TL, Schindeler A \& Munns C 2017 Combination sclerostin antibody and zoledronic acid treatment outperforms either treatment alone in a mouse model of osteogenesis imperfecta. Bone 101 96-103. (https:// doi.org/10.1016/j.bone.2017.04.016)

Lloyd SA, Loiselle AE, Zhang Y \& Donahue HJ 2013 Connexin 43 deficiency desensitizes bone to the effects of mechanical unloading through modulation of both arms of bone remodeling. Bone $\mathbf{5 7}$ 76-83. (https://doi.org/10.1016/j.bone.2013.07.022)

Loh NY, Neville MJ, Marinou K, Hardcastle SA, Fielding BA, Duncan EL, McCarthy MI, Tobias JH, Gregson CL, Karpe F, et al. 2015 LRP5 regulates human body fat distribution by modulating adipose progenitor biology in a dose- and depot-specific fashion. Cell Metabolism 21 262-273. (https://doi.org/10.1016/j.cmet.2015.01.009)

Loots GG, Kneissel M, Keller H, Baptist M, Chang J, Collette NM, Ovcharenko D, Plajzer-Frick I \& Rubin EM 2005 Genomic deletion of a long-range bone enhancer misregulates sclerostin in Van Buchem disease. Genome Research 15 928-935. (https://doi.org/10.1101/ gr.3437105)

Lovato C \& Lewiecki EM 2017 Emerging anabolic agents in the treatment of osteoporosis. Expert Opinion on Emerging Drugs 22 247-257. (https://doi.org/10.1080/14728214.2017.1362389)

Mabille C, Ruyssen-Witrand A, Degboe Y, Gennero I, Loiseau HA, Roussel M, Hebraud B, Nigon D, Attal M \& Laroche M 2018 DKK1 and sclerostin are early markers of relapse in multiple myeloma. Bone 113 114-117. (https://doi.org/10.1016/j.bone.2017.10.004)

McClung MR 2017 Sclerostin antibodies in osteoporosis: latest evidence and therapeutic potential. Therapeutic Advances in Musculoskeletal Disease 9 263-270. (https://doi.org/10.1177/1759720X17726744)

McClung MR, Grauer A, Boonen S, Bolognese MA, Brown JP, DiezPerez A, Langdahl BL, Reginster JY, Zanchetta JR, Wasserman SM, et al. 2014 Romosozumab in postmenopausal women with low bone mineral density. New England Journal of Medicine 370 412-420. (https://doi.org/10.1056/NEJMoa1305224)

McDonald MM, Reagan MR, Youlten SE, Mohanty ST, Seckinger A Terry RL, Pettitt JA, Simic MK, Cheng TL, Morse A, et al. 2017 Inhibiting the osteocyte-specific protein sclerostin increases bone mass and fracture resistance in multiple myeloma. Blood $\mathbf{1 2 9}$ 3452-3464. (https://doi.org/10.1182/blood-2017-03-773341)

Morrell AE, Brown GN, Robinson ST, Sattler RL, Baik AD, Zhen G, Cao X, Bonewald LF, Jin W, Kam LC, et al. 2018 Mechanically induced $\mathrm{Ca}(2+)$ oscillations in osteocytes release extracellular vesicles and enhance bone formation. Bone Research 6 6. (https://doi. org/10.1038/s41413-018-0007-x)

Niehrs C 2012 The complex world of WNT receptor signalling. Nature Reviews Molecular Cell Biology 13 767-779. (https://doi.org/10.1038/ nrm3470)

NIH Consensus Development Panel on Osteoporosis Prevention D \& Therapy 2001 Osteoporosis prevention, diagnosis, and therapy. JAMA 285 785-795.

Nusse R \& Clevers H 2017 Wnt/beta-Catenin Signaling, Disease, and Emerging Therapeutic Modalities. Cell 169 985-999. (https://doi. org/10.1016/j.cell.2017.05.016)

Ominsky MS, Brown DL, Van G, Cordover D, Pacheco E, Frazier E, Cherepow L, Higgins-Garn M, Aguirre JI, Wronski TJ, et al. 2015 Differential temporal effects of sclerostin antibody and parathyroid hormone on cancellous and cortical bone and quantitative differences in effects on the osteoblast lineage in young intact rats. Bone 81 380-391. (https://doi.org/10.1016/j.bone.2015.08.007)

Ominsky MS, Boyce RW, Li X \& Ke HZ 2017a Effects of sclerostin antibodies in animal models of osteoporosis. Bone 96 63-75. (https://doi.org/10.1016/j.bone.2016.10.019)

Ominsky MS, Boyd SK, Varela A, Jolette J, Felx M, Doyle N, Mellal N, Smith SY, Locher K, Buntich S, et al. 2017b Romosozumab improves bone mass and strength while maintaining bone quality in ovariectomized cynomolgus monkeys. Journal of Bone and Mineral Research 32 788-801. (https://doi.org/10.1002/jbmr.3036)

Paszty C, Turner CH \& Robinson MK 2010 Sclerostin: a gem from the genome leads to bone-building antibodies. Journal of Bone and Mineral Research 25 1897-1904. (https://doi.org/10.1002/jbmr.161)

Patel S, Barkell AM, Gupta D, Strong SL, Bruton S, Muskett FW, Addis PW, Renshaw PS, Slocombe PM, Doyle C, et al. 2018 Structural and functional analysis of Dickkopf 4 (Dkk4): new insights into Dkk evolution and regulation of Wnt signalling by Dkk and Kremen proteins. Journal of Biological Chemistry 293 12149-12166. (https:// doi.org/10.1074/jbc.RA118.002918)

Poole KE, van Bezooijen RL, Loveridge N, Hamersma H, Papapoulos SE, Lowik CW \& Reeve J 2005 Sclerostin is a delayed secreted product of osteocytes that inhibits bone formation. FASEB Journal 19 1842-1844. (https://doi.org/10.1096/fj.05-4221fje)

Prideaux M, Findlay DM \& Atkins GJ 2016 Osteocytes: the master cells in bone remodelling. Current Opinion in Pharmacology 28 24-30. (https://doi.org/10.1016/j.coph.2016.02.003)

Qin W, Li X, Peng Y, Harlow LM, Ren Y, Wu Y, Li J, Qin Y, Sun J, Zheng S, et al. 2015 Sclerostin antibody preserves the morphology and structure of osteocytes and blocks the severe skeletal deterioration after motor-complete spinal cord injury in rats. Journal of Bone and Mineral Research 30 1994-2004. (https://doi.org/10.1002/ jbmr.2549)

Qing H \& Bonewald LF 2009 Osteocyte remodeling of the perilacunar and pericanalicular matrix. International Journal of Oral Science $\mathbf{1}$ 59-65. (https://doi.org/10.4248/ijos.09019)

Ren Y, Han X, Ho SP, Harris SE, Cao Z, Economides AN, Qin C, Ke H, Liu M \& Feng JQ 2015 Removal of SOST or blocking its product sclerostin rescues defects in the periodontitis mouse model. FASEB Journal 29 2702-2711. (https://doi.org/10.1096/fj.14-265496)

Riggs BL \& Melton LJ, 3rd 1986 Involutional osteoporosis. New England Journal of Medicine 314 1676-1686. (https://doi.org/10.1056/ NEJM198606263142605)

Robling AG, Niziolek PJ, Baldridge LA, Condon KW, Allen MR, Alam I, Mantila SM, Gluhak-Heinrich J, Bellido TM, Harris SE, et al. 2008 Mechanical stimulation of bone in vivo reduces osteocyte expression of Sost/sclerostin. Journal of Biological Chemistry 283 5866-5875. (https://doi.org/10.1074/jbc.M705092200)

Roforth MM, Fujita K, McGregor UI, Kirmani S, McCready LK, Peterson JM, Drake MT, Monroe DG \& Khosla S 2014 Effects of age on bone mRNA levels of sclerostin and other genes relevant to bone metabolism in humans. Bone 59 1-6. (https://doi.org/10.1016/j. bone.2013.10.019)

Roudier M, Li X, Niu QT, Pacheco E, Pretorius JK, Graham K, Yoon BR, Gong J, Warmington K, Ke HZ, et al. 2013 Sclerostin is expressed in articular cartilage but loss or inhibition does not affect cartilage remodeling during aging or following mechanical injury. Arthritis and Rheumatism 65 721-731. (https://doi. org/10.1002/art.37802)

Saag KG, Petersen J, Brandi ML, Karaplis AC, Lorentzon M, Thomas T, Maddox J, Fan M, Meisner PD \& Grauer A 2017 Romosozumab or alendronate for fracture prevention in women with osteoporosis. New England Journal of Medicine 377 1417-1427. (https://doi. org/10.1056/NEJMoa1708322)

Salbach-Hirsch J, Samsonov SA, Hintze V, Hofbauer C, Picke AK, Rauner M, Gehrcke JP, Moeller S, Schnabelrauch M, Scharnweber D, et al. 2015 Structural and functional insights into sclerostinglycosaminoglycan interactions in bone. Biomaterials 67 335-345. (https://doi.org/10.1016/j.biomaterials.2015.07.021)

Sato AY, Cregor M, Delgado-Calle J, Condon KW, Allen MR, Peacock M, Plotkin LI \& Bellido T 2016 Protection from glucocorticoid-induced osteoporosis by anti-catabolic signaling in the absence of sost/ sclerostin. Journal of Bone and Mineral Research 31 1791-1802. (https://doi.org/10.1002/jbmr.2869) 
Semenov MV \& He X 2006 LRP5 mutations linked to high bone mass diseases cause reduced LRP5 binding and inhibition by SOST. Journal of Biological Chemistry 281 38276-38284. (https://doi.org/10.1074/ jbc.M609509200)

Semenov M, Tamai K \& He X 2005 SOST is a ligand for LRP5/LRP6 and a Wnt signaling inhibitor. Journal of Biological Chemistry $\mathbf{2 8 0}$ 26770-26775. (https://doi.org/10.1074/jbc.M504308200)

Shahnazari M, Wronski T, Chu V, Williams A, Leeper A, Stolina M, Ke HZ \& Halloran B 2012 Early response of bone marrow osteoprogenitors to skeletal unloading and sclerostin antibody. Calcified Tissue International 91 50-58. (https://doi.org/10.1007/ s00223-012-9610-9)

Spatz JM, Ellman R, Cloutier AM, Louis L, van Vliet M, Suva LJ, Dwyer D, Stolina M, Ke HZ \& Bouxsein ML 2013 Sclerostin antibody inhibits skeletal deterioration due to reduced mechanical loading. Journal of Bone and Mineral Research 28 865-874. (https://doi. org/10.1002/jbmr.1807)

Spatz JM, Wein MN, Gooi JH, Qu Y, Garr JL, Liu S, Barry KJ, Uda Y, Lai F, Dedic C, et al. 2015 The Wnt inhibitor sclerostin is up-regulated by mechanical unloading in osteocytes in vitro. Journal of Biological Chemistry 290 16744-16758. (https://doi.org/10.1074/ jbc.M114.628313)

Stolina M, Dwyer D, Niu QT, Villasenor KS, Kurimoto P, Grisanti M, Han CY, Liu M, Li X, Ominsky MS, et al. 2014 Temporal changes in systemic and local expression of bone turnover markers during six months of sclerostin antibody administration to ovariectomized rats. Bone 67 305-313. (https://doi.org/10.1016/j.bone.2014.07.031)

Suchacki KJ, Roberts F, Lovdel A, Farquharson C, Morton NM, MacRae VE \& Cawthorn WP 2017 Skeletal energy homeostasis: a paradigm of endocrine discovery. Journal of Endocrinology 234 R67-R79. (https://doi.org/10.1530/JOE-17-0147)

Sun Q, Choudhary S, Mannion C, Kissin Y, Zilberberg J \& Lee WY 2017 Ex vivo construction of human primary 3D-networked osteocytes. Bone 105 245-252. (https://doi.org/10.1016/j. bone.2017.09.012)

Sun Q, Choudhary S, Mannion C, Kissin Y, Zilberberg J \& Lee WY 2018 Ex vivo replication of phenotypic functions of osteocytes through biomimetic 3D bone tissue construction. Bone 106 148-155. (https:// doi.org/10.1016/j.bone.2017.10.019)

Sutherland MK, Geoghegan JC, Yu C, Turcott E, Skonier JE, Winkler DG \& Latham JA 2004 Sclerostin promotes the apoptosis of human osteoblastic cells: a novel regulation of bone formation. Bone $\mathbf{3 5}$ 828-835. (https://doi.org/10.1016/j.bone.2004.05.023)

Taylor S, Ominsky MS, Hu R, Pacheco E, He YD, Brown DL, Aguirre JI, Wronski TJ, Buntich S, Afshari CA, et al. 2016 Time-dependent cellular and transcriptional changes in the osteoblast lineage associated with sclerostin antibody treatment in ovariectomized rats. Bone 84 148-159. (https://doi.org/10.1016/j.bone.2015.12.013)

Terpos E, Christoulas D, Katodritou E, Bratengeier C, Gkotzamanidou M, Michalis E, Delimpasi S, Pouli A, Meletis J, Kastritis E, et al. 2012 Elevated circulating sclerostin correlates with advanced disease features and abnormal bone remodeling in symptomatic myeloma: reduction post-bortezomib monotherapy. International Journal of Cancer 131 1466-1471. (https://doi.org/10.1002/ijc.27342)

Tian E, Zhan F, Walker R, Rasmussen E, Ma Y, Barlogie B \& Shaughnessy JD Jr 2003 The role of the Wnt-signaling antagonist DKK1 in the development of osteolytic lesions in multiple myeloma. New England Journal of Medicine 349 2483-2494. (https://doi. org/10.1056/NEJMoa030847)

Trinh S, Balani DH, Boyce R \& Kronenberg HM 2017 Sclerostin antibody administration increases the Numbers and Differentiation of Osteoblast Precursors in Vivo. Journal of Bone and Mineral Research 32 Supplement 1ABSTRACT 1142.

Truswell AS 1958 Osteopetrosis with syndactyly; a morphological variant of Albers-Schonberg's disease. Journal of Bone and Joint Surgery. British Volume 40-B 209-218.
Tu X, Delgado-Calle J, Condon KW, Maycas M, Zhang H, Carlesso N, Taketo MM, Burr DB, Plotkin LI \& Bellido T 2015 Osteocytes mediate the anabolic actions of canonical Wnt/beta-catenin signaling in bone. PNAS 112 E478-E486. (https://doi.org/10.1073/ pnas.1409857112)

van Bezooijen RL, Deruiter MC, Vilain N, Monteiro RM, Visser A, van der Wee-Pals L, van Munsteren CJ, Hogendoorn PC, Aguet M, Mummery CL, et al. 2007 SOST expression is restricted to the great arteries during embryonic and neonatal cardiovascular development. Developmental Dynamics 236 606-612. (https://doi.org/10.1002/ dvdy.21054)

van Bezooijen RL, Bronckers AL, Gortzak RA, Hogendoorn PC, van der Wee-Pals L, Balemans W, Oostenbroek HJ, Van Hul W, Hamersma H, Dikkers FG, et al. 2009 Sclerostin in mineralized matrices and van Buchem disease. Journal of Dental Research 88 569-574. (https://doi. org/10.1177/0022034509338340)

Van Buchem FS, Hadders HN \& Ubbens R 1955 An uncommon familia systemic disease of the skeleton: hyperostosis corticalis generalisata familiaris. Acta Radiologica 44 109-120. (https://doi. org/10.3109/00016925509170789)

Van Hul W, Balemans W, Van Hul E, Dikkers FG, Obee H, Stokroos RJ, Hildering P, Vanhoenacker F, Van Camp G \& Willems PJ 1998 Van Buchem disease (hyperostosis corticalis generalisata) maps to chromosome 17q12-q21. American Journal of Human Genetics 62 391-399. (https://doi.org/10.1086/301721)

van Lierop AH, Appelman-Dijkstra NM \& Papapoulos SE 2017 Sclerostin deficiency in humans. Bone 96 51-62. (https://doi.org/10.1016/j. bone.2016.10.010)

Van Wesenbeeck L, Cleiren E, Gram J, Beals RK, Benichou O, Scopelliti D, Key L, Renton T, Bartels C, Gong Y, et al. 2003 Six novel missense mutations in the LDL receptor-related protein 5 (LRP5) gene in different conditions with an increased bone density. American Journal of Human Genetics 72 763-771. (https://doi. org/10.1086/368277)

Veverka V, Henry AJ, Slocombe PM, Ventom A, Mulloy B, Muskett FW, Muzylak M, Greenslade K, Moore A, Zhang L, et al. 2009 Characterization of the structural features and interactions of sclerostin: molecular insight into a key regulator of Wnt-mediated bone formation. Journal of Biological Chemistry 284 10890-10900. (https://doi.org/10.1074/jbc.M807994200)

Wang XT, He YC, Zhou SY, Jiang JZ, Huang YM, Liang YZ \& Lai YR 2014 Bone marrow plasma macrophage inflammatory protein protein-1 alpha(MIP-1 alpha) and sclerostin in multiple myeloma: relationship with bone disease and clinical characteristics. Leukemia Research $\mathbf{3 8}$ 525-531. (https://doi.org/10.1016/j.leukres.2014.02.010)

Wang K, Tiede-Lewis L, McCormick L, Lara N, Keightley A, Farina N, Huang J, Lian J, Brotto M, Bonewald L, et al. 2017 Extracellular vesicle-mediated cell-cell communication in bone and potential role in muscle-bone crosstalk. Journal of Bone and Mineral Research 32 Supplement 1 ABSTRACT 1149.

Wehmeyer C, Frank S, Beckmann D, Bottcher M, Cromme C, Konig U, Fennen M, Held A, Paruzel P, Hartmann C, et al. 2016 Sclerostin inhibition promotes TNF-dependent inflammatory joint destruction. Science Translational Medicine 8 330ra335. (https://doi.org/10.1126/ scitranslmed.aac4351)

Wei J \& Karsenty G 2015 An overview of the metabolic functions of osteocalcin. Current Osteoporosis Reports 13 180-185. (https://doi. org/10.1007/s11914-015-0267-y)

Weidauer SE, Schmieder P, Beerbaum M, Schmitz W, Oschkinat H \& Mueller TD 2009 NMR structure of the Wnt modulator protein Sclerostin. Biochemical and Biophysical Research Communications $\mathbf{3 8 0}$ 160-165. (https://doi.org/10.1016/j.bbrc.2009.01.062)

Wijenayaka AR, Kogawa M, Lim HP, Bonewald LF, Findlay DM \& Atkins GJ 2011 Sclerostin stimulates osteocyte support of osteoclast activity by a RANKL-dependent pathway. PLOS ONE 6 e25900. (https://doi.org/10.1371/journal.pone.0025900) 
Winkler DG, Sutherland MK, Geoghegan JC, Yu C, Hayes T, Skonier JE, Shpektor D, Jonas M, Kovacevich BR, Staehling-Hampton K, et al. 2003 Osteocyte control of bone formation via sclerostin, a novel BMP antagonist. EMBO Journal 22 6267-6276. (https://doi. org/10.1093/emboj/cdg599)

Woo SM, Rosser J, Dusevich V, Kalajzic I \& Bonewald LF 2011 Cell line IDG-SW3 replicates osteoblast-to-late-osteocyte differentiation in vitro and accelerates bone formation in vivo. Journal of Bone and Mineral Research 26 2634-2646. (https://doi.org/10.1002/jbmr.465)

Woods GN, Ewing SK, Sigurdsson S, Kado DM, Ix JH, Hue TF, Eiriksdottir G, Xu K, Gudnason V, Lang TF, et al. 2018 Chronic kidney disease is associated with greater bone marrow adiposity. Journal of Bone and Mineral Research. (https://doi.org/10.1002/jbmr.3562)

Yorgan TA, Peters S, Jeschke A, Benisch P, Jakob F, Amling M \& Schinke T 2015 the anti-osteoanabolic function of sclerostin is blunted in mice carrying a high bone mass mutation of Lrp5. Journal of Bone and Mineral Research 30 1175-1183. (https://doi.org/10.1002/ jbmr.2461)

Zhang D, Park BM, Kang M, Nam H, Kim EJ, Bae C \& Lim SK 2016 The systemic effects of sclerostin overexpression using PhiC31 integrase in mice. Biochemical and Biophysical Research Communications 472 471-476. (https://doi.org/10.1016/j.bbrc.2016.01.178)

Zhou H, Yang M, Li M \& Cui L 2017 Radial artery sclerostin expression in chronic kidney disease stage 5 predialysis patients: a crosssectional observational study. International Urology and Nephrology 49 1433-1437. (https://doi.org/10.1007/s11255-017-1604-0)

Zhu D, Mackenzie NC, Millan JL, Farquharson C \& MacRae VE 2011 The appearance and modulation of osteocyte marker expression during calcification of vascular smooth muscle cells. PLOS ONE 6 e19595. (https://doi.org/10.1371/journal.pone.0019595)

Received in final form 25 September 2018

Accepted 17 October 2018
(C) 2019 Society for Endocrinology Published by Bioscientifica Ltd. Printed in Great Britain 